\title{
Polypharmacology of some medicinal plant metabolites against SARS-CoV-2 and host targets: Molecular dynamics evaluation of NSP9 RNA binding protein
}

Authors: Suritra Bandyopadhyay, ${ }^{1,2}$, Omobolanle Abimbola Abiodun ${ }^{3}$, Blessing Chinweotito $\mathrm{Ogboo}^{4}$, Adeola Tawakalitu Kola-Mustapha ${ }^{5,6}$, Emmanuel Ifeanyi Attah ${ }^{7}$, Lawrence Edemhanria $^{8}$, Ankita Kumari ${ }^{9}$, Ravindran Jaganathan ${ }^{10,11}$, Niyi S. Adelakun ${ }^{3,12}$

${ }^{1}$ School of Chemical Sciences, National Institute of Science Education and Research, Bhubaneswar, India. (ORCID: 0000-0001-9408-9816)

${ }^{2}$ Homi Bhabha National Institute (HBNI), Mumbai, India.

${ }^{3}$ Department of Biochemistry, Adekunle Ajasin University, Akungba-Akoko, Ondo State, Nigeria.

${ }^{4}$ Department of Pure and Industrial Chemistry, Faculty of Physical Sciences, University of Nigeria, Nsukka.

${ }^{5}$ Department of Pharmaceutics, Faculty of Pharmaceutical Sciences, University of Ilorin, Ilorin, Nigeria (ORCID: 0000-0001-8281-470X)

${ }^{6}$ College of Pharmacy, Alfaisal University Riyadh, Saudi Arabia

7 Department of Pharmaceutical and Medicinal Chemistry, Faculty of Pharmaceutical Sciences, University of Nigeria, Nsukka (ORCID: 0000-0003-1422-0621)

8 Department of Chemical Sciences, Samuel Adegboyega University, Ogwa, Nigeria (ORCID: 0000-0002-6034-3780)

${ }^{9}$ Bionivid Technology Pvt. Ltd., Kasturi Nagar, Bangalore, India

${ }^{10}$ SriSamraj Health Services Pvt. Ltd., Tindivanam-604001, Tamilnadu, India.

${ }^{11}$ Pre-clinical Department, Faculty of Medicine, Royal College of Medicine Perak, Universiti Kuala Lumpur (UniKL-RCMP), Malaysia (ORCID: 0000-0002-2654-1855)

${ }^{12}$ Bio-Assay and Cheminformatics Unit, Molecular and Simulations, Ado-Ekiti, Ekiti State, Nigeria.

Corresponding Author: Niyi S. Adelakun

Telephone: Niyi S Adelakun: (+234) 8077589705

Postal Address: Bio-Assay and Cheminformatics Unit, Molecular and Simulations, Ado-Ekiti, Ekiti State, Nigeria.

E-mail address: 13040105@aaua.edu.ng 


\section{Abstract}

Background: Medicinal plants, as rich sources of bioactive compounds with antiviral properties, are now being explored for the development of drugs against SARS-CoV-2.

Aims: Identification of promising compounds for the treatment of COVID-19 from natural products via molecular modelling against NSP9, including some other viral and host targets and evaluation of polypharmacological indications.

Main methods: A manually curated library of 521 phytochemicals (from 19 medicinal plants) was virtually screened using Mcule server and binding interactions were studied using DS Visualiser. Docking thresholds were set based on the scores of standard controls and rigorous ADMET properties were used to finally get the potential inhibitors. Free binding energies of the docked complexes were calculated employing MM-GBSA method. MM-GBSA informed our choice for MD simulation studies performed against NSP9 to study the stability of the drug-receptor interaction. NSP9 structure comparison was also performed.

Key findings: Extensive screening of the molecules identified 5 leads for NSP9, 23 for Furin, 18 for ORF3a, and 19 for interleukin-6. Ochnaflavone and Licoflavone B, obtained from Lonicera japonica (Japanese Honeysuckle) and Glycyrrhiza glabra (Licorice), respectively, were identified to have the highest potential multi-target inhibition properties for NSP9, furin, ORF3a, and IL-6. Additionally, molecular dynamics simulation supports the robust stability of Ochnaflavone and Licoflavone B against NSP9 at the active sites via hydrophobic interactions, H-bonding, and H-bonding facilitated by water.

Significance: These compounds with the highest drug-like ranking against multiple viral and host targets have the potential to be drug candidates for the treatment of SARS-CoV-2 infection that may possibly act on multiple pathways simultaneously to inhibit viral entry and replication as well as disease progression.

Keywords: Virtual Screening, ORF3a, NSP9, Furin, IL-6, Phytochemicals, Molecular Dynamics Simulation, COVID-19 


\section{Introduction}

COVID-19 was first reported in Wuhan, China in December 2019 and declared a global pandemic by the World Health Organization (WHO) in March 2020 (Cucinotta and Vanelli, 2020; Li et al., 2020). The global outlook reported by ECDC as of 28 August 2020, was 24,473,843 confirmed cases and 832,002 deaths among continents (www.ecdc.europa.eu) represented in Figure 1.

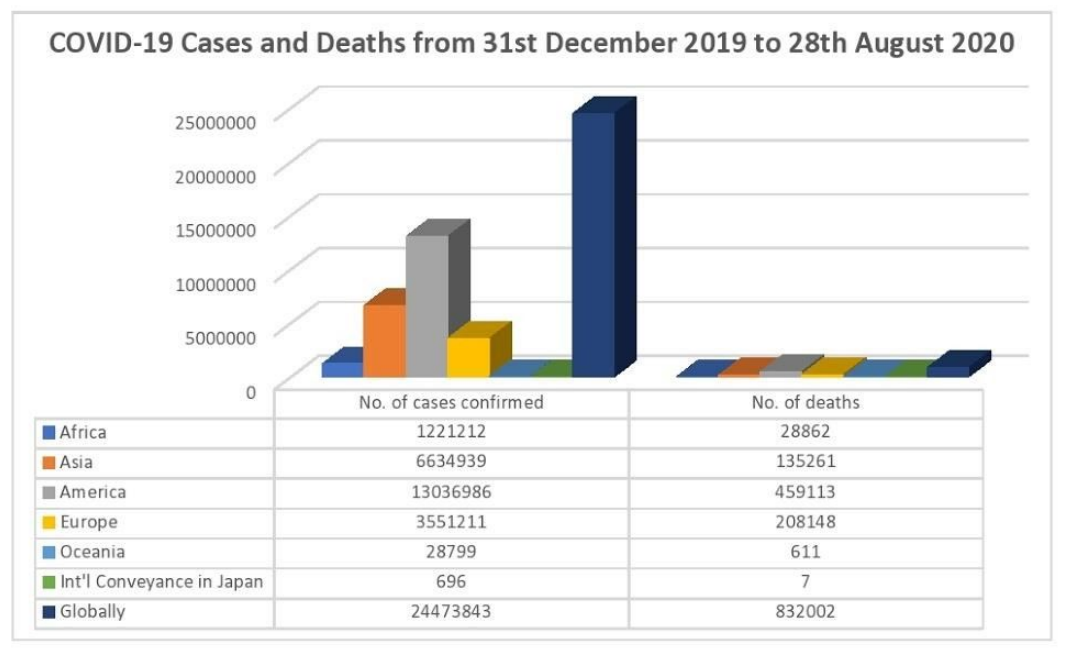

Figure 1. COVID-19 situation report till 28 August 2020. SARS CoV-2 virus disease cases and deaths. Data are based on official information reported by the European Center for Disease Prevention and Control.

The global challenge to health and economy posed by COVID-19 may only be upturned by the development of an effective drug or vaccine for its management. To date, no drug or vaccine has been approved to treat COVID-19. Highly exploited drug targets for COVID-19 include Receptor Binding Domain (RBD) (Dong et al., 2020), spike protein (S), nucleocapsid (N) (Grunewald et al., 2018, Surjit et al., 2006), non-structural proteins (NSPs) including papain-like protease (Plpro), RNA-dependent RNA polymerase (RdRp), 3-chymotrypsin-like protease (3Clpro). The non-structural proteins 9 (NSP9) replicase is among the 16 NSPs of SARS-CoV-2 vital for viral replication and transcription (Ziebuhr et al., 2000). Also, unlike other proteins with a single domain, it comprises a unique single folded beta-barrel. It binds with RNA, interacts further with NSP8, and triggers the essential functions (Sutton et al., 2004). Inhibition of NSP9 further inhibits NSP8 and thereby antagonizes viral replication making it one of the attractive targets for drug discovery. Our interest was NSP9 because of its uncharacterized function in the domain of replication. ORF3a is also an interesting target for drug discovery. It plays an essential role in induced cell apoptosis and activation of NLRP3 inflammasome (Siu et al., 2019), leading to cytokine storms.

Besides the viral targets, there are host proteins that aid viral replication and promote an excessive inflammatory response. Identification of potential inhibitors of host factors has been less explored via computational studies (Wu et al., 2020; Rahman et al., 2020) when compared with the studies on viral proteins inhibition. Among various host targets (Carmen et al., 2020), we were interested in studying the receptors, furin that plays a major role in activating the 
S-proteins, implicated in the cleavage and activation of viral coat proteins (Cameron et al. 2000), and interleukin-6, a cytokine with a crucial role in virus-induced immunopathological events which causes fatal pneumonia in severe SARS-Cov-2 infections (Channappanavar and Perlman, 2020).

The interaction of drug molecules with multiple targets have been described as polypharmacology. It represents a new lead to rational designing of the next cohort of therapeutic agents with improved efficacy and decreased toxicity. The past decade witnessed a paradigm shift in the drug discovery process as regards solely targeting disease with one drug. Lack of efficacy and high toxicity had been the reasons for the rejection of new drug applications, hence the need for this paradigm change. The rational designs of multi-target ligands have been challenging to achieve. However, their benefits over the use of selective compounds include improved efficacy and less complicated pharmacodynamic and pharmacokinetic characteristics when compared to a number of drug combinations (Proschak, 2014).

Plants are rich sources of bioactive compounds that are reported to be effective against numerous pathogens (Hussain et al., 2017). In this context, we present a virtual screening of small-drug like plant metabolites against four chosen targets: NSP9, ORF3a, furin, and IL-6, and the analysis of their polypharmacological indications. We compared the structure of SARS-2 NSP9 against SARS Cov and H-Cov and examined the nature and properties of the binding pockets of all the chosen receptors. A Molecular Dynamics (MD) simulation study was executed to validate the findings and investigate the stability of the NSP9 protein-ligand complexes.

\section{Materials and Methods}

Determination of NSP9 sequence percentage identity, multiple sequence alignment, and pairwise structural clustering

The three-dimensional structures of SARS-CoV-2 NSP9, SARS-CoV (HKU 39849) NSP9 and H-CoV 229E NSP9 were retrieved from Protein Data Bank (PDB) (http://www.rcsb.org/) using PDB IDs: 6W4B, $1 \mathrm{UW7}$ and $2 \mathrm{~J} 97$ at a resolution of $2.95 \AA$, $2.80 \AA$ and $1.75 \AA$ respectively. The sequence percentage identity of the SARS-CoV-2 NSP9 to SARS-CoV (HKU-39849) NSP9 and H-CoV (229E). NSP9 was evaluated using a standard protein Basic Local Alignment Search (BLASTp) tool (https://blast.ncbi.nlm. nih.gov/Blast.cgi?PAGE=Proteins) as presented in Table 1. Multiple sequence alignment of the three sequences of NSP9 were performed using Clustal $\Omega$ from the MPI Bioinformatics toolkit (Zimmermann et al., 2018, Sievers et al., 2011). EduPyMol version 2.3.4 (The PyMOL Molecular Graphics System, Version 2.3.4, Schrödinger, LLC.) was used to align the proteins and analyze the pairwise structural clustering of SARS-2 NSP9 with SARS NSP9 and H-CoV NSP9. 
Table 1 Standard Protein BLAST output using SARS-CoV-2 NSP9, PDB: 6W4B as the query sequence.

\begin{tabular}{|c|c|c|c|c|c|c|c|}
\hline Subject Sequence & $\begin{array}{c}\text { PDB Accession } \\
\text { IDs }\end{array}$ & $\begin{array}{l}\text { Percent } \\
\text { Identity }\end{array}$ & $\begin{array}{c}\text { Query Coverage } \\
(\%)\end{array}$ & $\begin{array}{c}\text { Mismatche } \\
\mathrm{s}\end{array}$ & $\begin{array}{l}\text { Gap } \\
\text { Opens }\end{array}$ & $\begin{array}{c}\text { E-Valu } \\
\text { e }\end{array}$ & $\begin{array}{l}\text { Bit } \\
\text { Score }\end{array}$ \\
\hline$\frac{\text { SARS coronavirus }}{\underline{\text { HKU-39849 }}}$ & 1UW7_A & 97.345 & 96 & 3 & 0 & $\begin{array}{c}3.26 \mathrm{E}-8 \\
0\end{array}$ & 232 \\
\hline$\frac{\text { Human coronavirus }}{\underline{229 \mathrm{E}}}$ & 2J97_A & 44.248 & 96 & 59 & 2 & $\begin{array}{c}2.55 \mathrm{E}-2 \\
7\end{array}$ & 97.8 \\
\hline
\end{tabular}

\section{Dataset and ligand preparation}

Phytochemicals from 19 different medicinal plants with potential antiviral and anti-inflammatory activities obtained through literature survey were compiled and manually curated to get a comprehensive database of 521 non-redundant molecules. Table S1 (SI) enlists all the plants with their taxonomic identities. The 2D structures of the compounds were retrieved from PubChem Database (Kim et al., 2019), and the database of molecules was prepared by uploading the retrieved structures. As controls for the screening study, standard inhibitors (Table 3) for all the four receptors were downloaded from PubChem. They were minimized by the conjugate gradient algorithm using the minimize function of Open Babel (Boyle et al., 2011) prior to docking.

\section{Evaluation of the binding site}

Four receptors, including two from SARS-CoV-2: NSP9 and ORF3a and two from the host: furin and IL-6, were chosen for our study. The protein PDB structures of the receptors with PDB IDs 5JXI, 1ALU, 6XDC, and 6W4B with resolutions $2.00 \AA ⿻ 1.9 \AA, 2.9 \AA$ and $2.95 \AA$ respectively were downloaded from Research Collaboratory for Structural Bioinformatics Protein Data Bank (RSCB PDB; (http://www.rcsb.org/, Berman et al., 2000). The active pockets of the viral targets, NSP9 and ORF3a with PDB IDs 6W4B and 6XDC respectively, were predicted using SiteMap (Schrödinger Release 2018-1: SiteMap, Schrödinger, LLC, New York, USA).

Potential binding regions and active residues of the host receptors, IL-6 and furin with PDB IDs 1ALU and 5JXI respectively, have been previously identified, experimentally verified, and resolved in high-resolution crystals. The pockets and residues identified in the active site were further evaluated using ConSurf (Ashkenazy et al., 2016; Celniker et al., 2013; Ashkenazy et al., 2010) and PrankWeb (Jendele et al., 2019; Krivak et al., 2018) online servers.
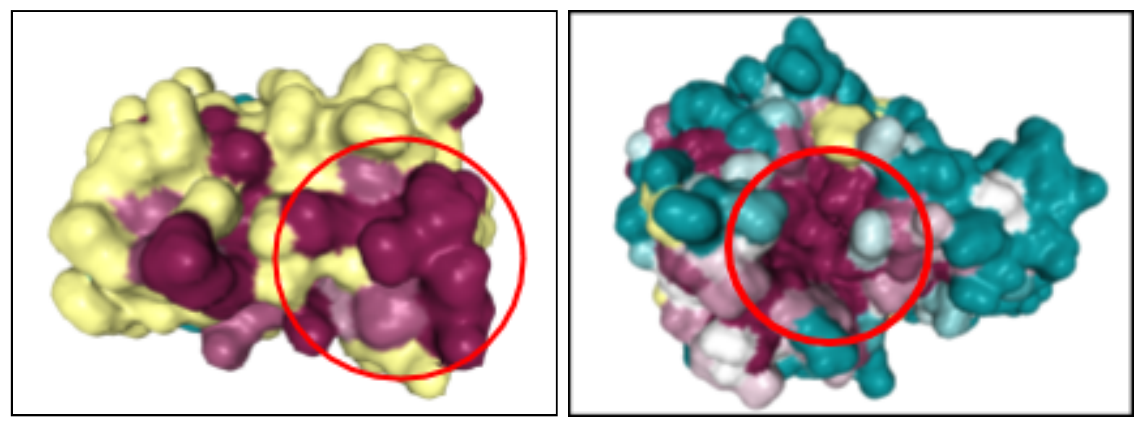
(a)

(b)

Figure 2. Predicted conserved regions of the target (a) IL-6 [1ALU:A] and (b) Furin [5JXI]. The region marked in shades of purple corresponds to the conserved residues, while shades of cyan correspond to variable amino acid residues. The region in yellow doesn't have sufficient information for conservation analysis. Encircled in red is the active site for the host receptors from reported literature.

\section{Receptor preparation}

Chain A of the polymeric-proteins was chosen for further molecular docking and screening studies. Prior to virtual screening, the protein molecules were cleaned and prepared using AutoDock Tools 1.5.6 (Sanner et al., 1999; Morris et al., 2009). All the non-polar hydrogens, lone-pairs, water molecules, and non-standard residues were removed. Polar hydrogens were added, followed by the addition and merging of Gasteiger charges. The files were exported and saved as pdbqt.

The Grid configuration parameters were also generated using AutoDock Tools 1.5.6. For each receptor, the GridBox was set near the active site region, and the size of the box was relaxed, ensuring the inclusion of all essential catalytic, conserved structural motifs and substrate binding amino acid residues inside the box that are vital for the functioning of the receptors to reduce the search space for ligand optimization (Trott and Olson, 2010). A grid point spacing of $0.375 \AA$ was used, the grid dimensions and the coordinates of the grid box center for all the targets were preserved for virtual screening represented in Table 2.

Table 2. Grid Box Dimensions for Virtual Screening Study

\begin{tabular}{|c|c|c|c|c|}
\hline $\begin{array}{c}\text { Recepto } \\
\mathbf{r}\end{array}$ & $\begin{array}{c}\text { PDB } \\
\text { ID }\end{array}$ & $\begin{array}{c}\text { Grid } \\
\text { Points }\end{array}$ & $\begin{array}{c}\text { Grid Box Configurations } \\
\text { coordinates) }\end{array}$ & $\begin{array}{c}\text { Gridpoint Spacing } \\
(\AA)\end{array}$ \\
\hline IL-6 & 1ALU & $50 \times 50 \times 50$ & $-7.608,-13.445,-0.009$ & 0.375 \\
\hline Furin & 5 JXI & $50 \times 50 \times 50$ & $47.439,-37.435,-6.882$ & 0.375 \\
\hline ORF3a & 6 6XDC & $50 \times 50 \times 50$ & $137.956,133.843,145.017$ & 0.375 \\
\hline NSP9 & 6 6W4B & $40 \times 40 \times 40$ & $44.507,-8.293,12.412$ & 0.375 \\
\hline
\end{tabular}

\section{Virtual screening workflow}

Structure-based virtual screening (SBVS) of the prepared phytochemical library was performed using custom workflows of Mcule Drug Discovery Pipeline (http://Mcule.com; Kiss et al., 2012). The Mcule server utilized the 3D structure of the target and fitted the ligands by efficiently using a gradient optimization method in its local optimization procedure. The individual workflow steps were added to filter the hits for this study, namely the basic property filter search based on the number of rule-of-five (RO5) violations and the Docking (Vina) workflow step (Trott and Olson, 2010), were sequentially executed. 


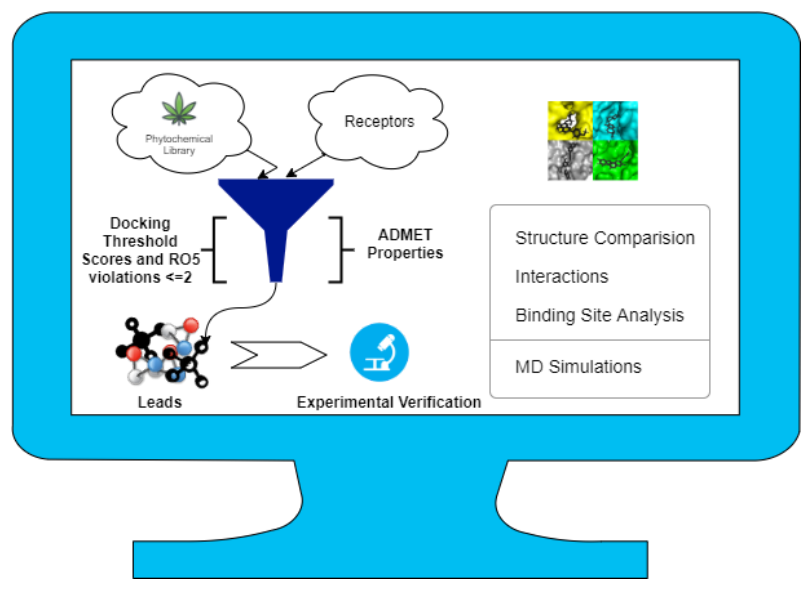

Figure 3. Schematic representation of the workflow

It has been opined that Lipinski's rule (RO5) has been overstated in its role as a tool, guiding the drug design of small molecules that are orally bioavailable. The reasons include: about half of small molecule drugs that are FDA approved are administered orally and obey the RO5, which excludes essential biologicals. Also, the RO5 excludes natural products that make up about $33 \%$ of commercially available small molecule drugs. Therefore, the focus on research applicable to natural products should be encouraged (Zhang and Wilkinson, 2007). It is also pertinent to remember that RO5 doesn't predict pharmacological activity; hence restricting the drug discovery space would not just limit the search but would result in the exclusion of certain compounds that would otherwise possess immense pharmacological potentials. Very recently, for areas with large unmet medical needs like oncology and virology, extensive studies show the focus and demands of beyond-rule-of-five drug candidates. To broaden the search of our study for finding anti-COVID phytochemical candidates, we have allowed a maximum balanced violation of two.

The molecules were screened by docking using the Vina docking algorithm (Trott and Olson, 2010). The receptor targets were prepared and fed as an input file. The grid dimensions, as well as the coordinates of the center of the binding site for each receptor molecule was fed to the workflow step, and other constraints required were set to default. For the inhibitors used as controls, molecular docking was manually performed using AutoDock Vina.

\section{Post-docking visualization and binding site analysis}

The structures of the top conformation of the docked Phyto-ligands complexed with the receptor macromolecules having the lowest binding affinity values (Vina docking scores) were retrieved from Mcule, and the poses were visualized using EduPyMol version 2.3.4. The top screened molecules were further analyzed for the receptor-ligand interactions (with the binding site residues), the type of bonds, the bond distances, using the various functionalities available in Discovery Studio Visualiser 2020. Among multiple interactions, we mainly looked for the non-covalent interaction, including the occurrences of hydrogen, Vanderwaal, $\pi-\pi$ 
interaction, $\pi$-sigma bond, $\pi$-sulfur, and many other hydrophobic interactions among the other existing ones. The characteristics of the binding site pocket were also of interest and hence were analyzed for the nature of aromaticity, H-bond donor/acceptor distribution, hydrophobicity, and solvent accessibility (SAS) using DS Visualiser.

\section{Molecular dynamics simulation.}

For the challenges with respect to the computational expenses, we chose NSP9 for further evaluation mainly because we were interested to understand the dynamics of the binding site residues of a viral protein that has not been appropriately characterised concerning its biological function. Molecular dynamics simulations were performed using Desmond tool (Bowers et al., 2006; Desmond Molecular Dynamics System, D. E. Shaw Research, New York, NY; Maestro-Desmond Interoperability Tools, Schrödinger, New York, NY, 2018). The ligand-receptor complex was placed at the center of a periodic orthorhombic box, and the addition of TIP3 water molecules performed solvation. Sodium and chloride ions were added to neutralize the system at a concentration of $0.15 \mathrm{M}$ to mimic physiological conditions. For long-range electrostatics, the smooth particle mesh Ewald (PME) estimation was used, while for nonbonded interactions at a cut-off of $9 \AA$ MSHAKE algorithm was utilized. The Default Desmond protocol was followed for system relaxation. After energy minimization, the system was gradually heated to a temperature of 300K. It was maintained by Nose-Hoover thermostat for a constant number of particles, volume, and temperature simulation of 500ps with $2 \mathrm{fs}$ time step, followed by equilibration of pressure to 1 bar and was maintained via Martyna-Tuckerman-Klein barostat, during constant number of particles, pressure, and temperature (NPT) of 500ps with $2 \mathrm{fs}$ time step. MD Simulation was performed for each of the three protein-ligand complexes and the apo-state protein for $100 \mathrm{~ns}$ with $2 \mathrm{fs}$ time step. Computation of the trajectories was executed using multiple time-step RESPA integrators. We analyzed the root mean square deviation (RMSD) and root mean square fluctuation (RMSF) of the main backbone of carbon atoms, RMSD of the ligands and the protein-ligand contacts were also assessed. Simulation results analysis was performed using the Desmond SID in maestro.

\section{ADMET properties}

The resultant library generated after the virtual screening and the benchmark docking scores for all the four receptors were subjected to in silico predictions of pharmacokinetics and ADMET properties using the admetSAR 2.0 webserver (Yang et al., 2019). The molecules were specifically checked for human intestinal absorption, blood-brain barrier permeance, phosphoglycoprotein substrate binding, cytochrome inhibition (CYP2D6), carcinogenicity, and AMES mutagenicity to give us the final leads for the receptors.

\section{Rodent acute toxicity studies}

In silico prediction of acute toxicity in rodent models for the molecules with possible polypharmacological prospects was performed using the GUSAR webserver (Languin et al., 2011). Using GUSAR, compounds can be evaluated based on the Quantitative Neighborhoods of Atoms Descriptors and Prediction of Activity Spectra for substances algorithm. The result thus obtained will be correlated using the SYMYX MDL toxicity database. Further, it is 
Polypharmacology of some medicinal plant metabolites against SARS-CoV-2 and host targets: Molecular dynamics evaluation of NSP9 RNA binding protein

classified using the chemical classification manual of the Organisation for Economic Co-operation and Development (OECD) (Salman, et al. 2020). 


\section{Results and Discussions}

\section{Comparative analysis of SARS-CoV-2 NSP9, SARS-CoV NSP9, and H-CoV NSP9 at the sequence and structural level}

The comparison at the sequence level for NSP9 protein structures of SARS-2 against SARS and $\mathrm{H}-\mathrm{CoV}$ is shown in Figure 4. The sequence of SARS-CoV-2 NSP9 (6W4B) protein structure was run for a protein Basic Local Alignment Search in NCBI (BLASTp) where we got a sequence percentage identity of $97.35 \%$ for the SARS CoV (HKU-39849) NSP9 with PDB ID 1UW7 and $44.25 \%$ for the NSP9 of H-CoV 229E with PDB ID 2J97 (Table 1). Upon aligning the proteins in EduPyMol program, we got a MatchAlign score of 556 for SARS2-SARS NSP9 with an executive RMSD of 0.707 while a MatchAlign score of 220 was obtained for SARS2-HCoV NSP9 superimposition with an executive RMSD of 1.522. This result indicates that SARS-CoV-2 NSP9 is structurally more close to SARS-CoV NSP9 as compared to H-CoV NSP9 (Figure 4). The analysis can be further utilized for the design of broad-spectrum inhibitors for the prevention of the host cell attack (Gurung et al., 2020). Further, MSA results demonstrate the areas of conservation and disagreement in Figure 5.
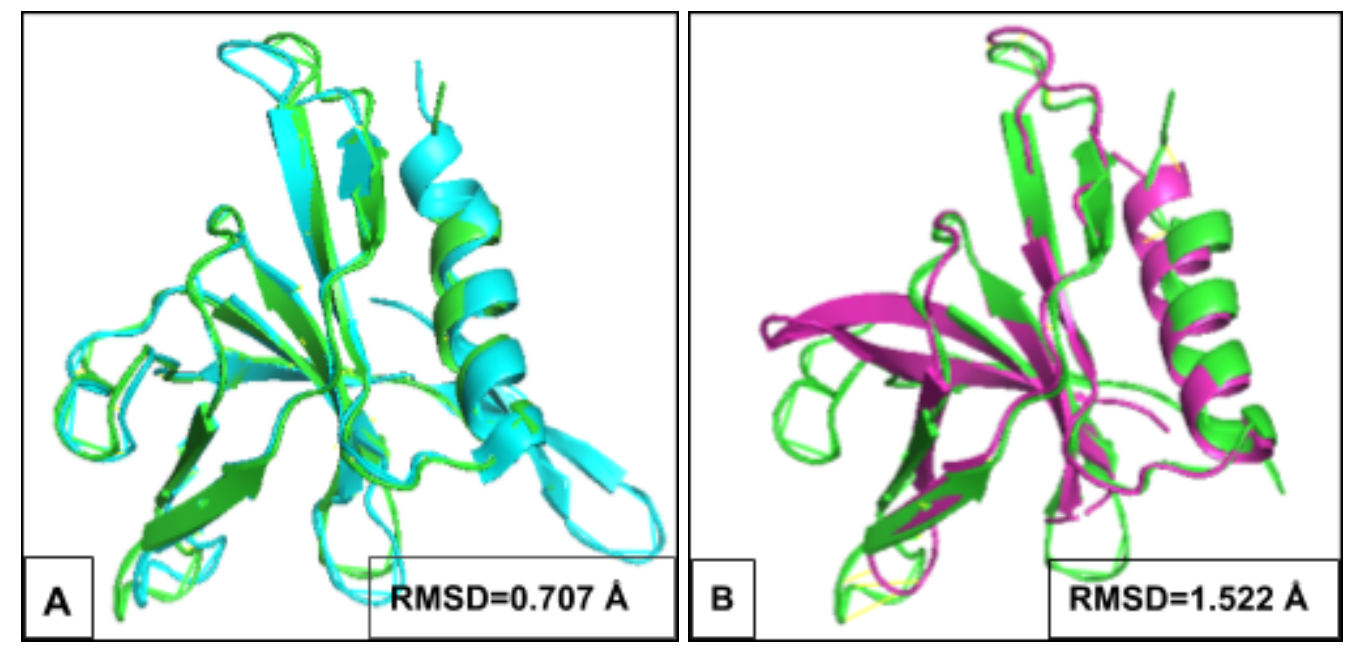

Figure 4. Structural clustering- (A) SARS-CoV-2 NSP9 (green) and SARS-CoV NSP9 (cyan),

(B) SARS-CoV-2 NSP9 (green) and H-CoV NSP9 (magenta). The structure is discontinuous at the sites of disagreements 

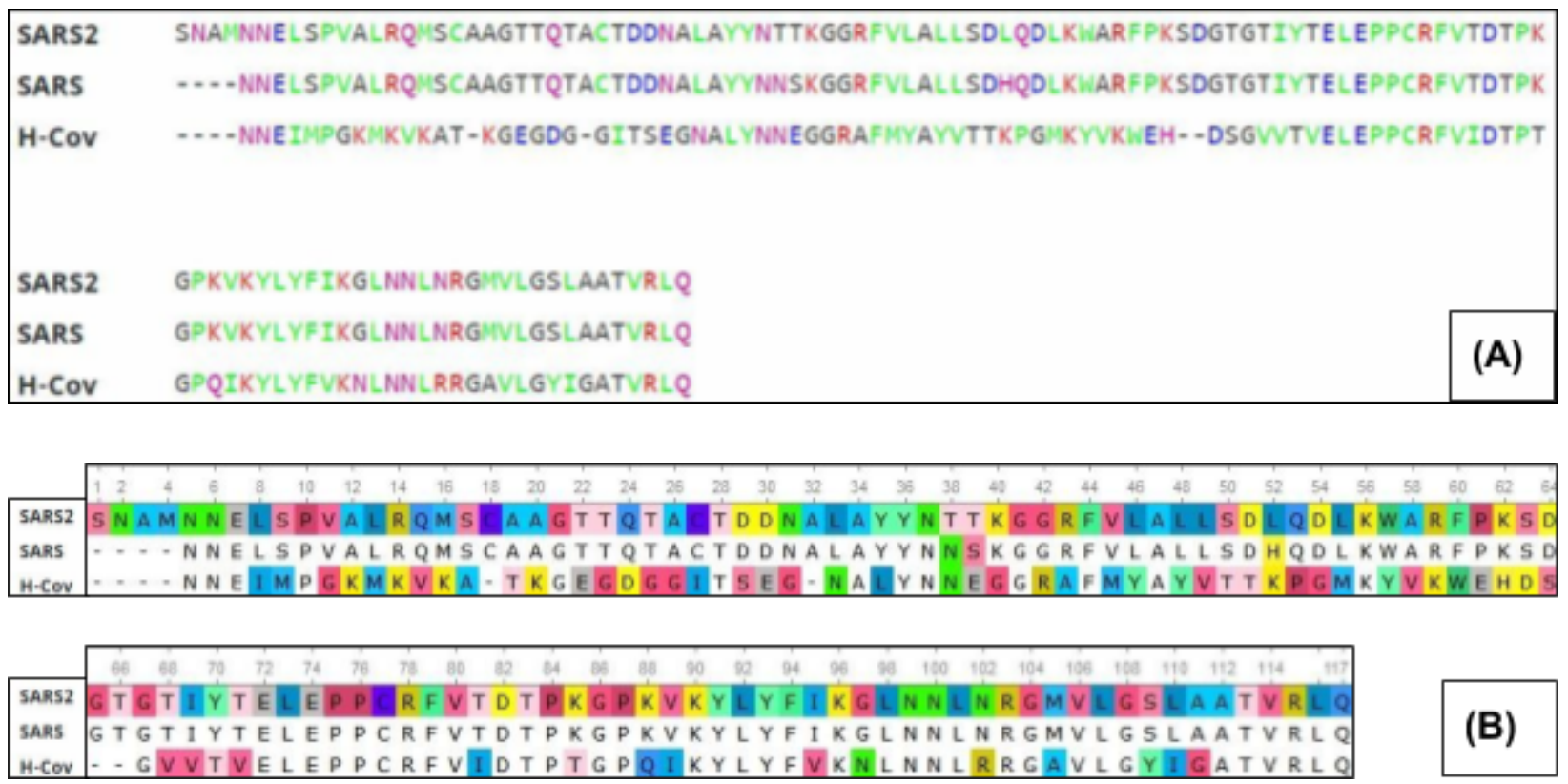

Figure 5. Multiple sequence alignment (MSA) of SARS-CoV-2 NSP9, SARS-CoV NSP9, and H-CoV NSP9.

(A) The MSA highlights the conserved amino acid residues

(B) The image highlights the disagreements of the NSP9 SARS Cov and H-Cov

(viewed via Unipro UGENE)

\section{Binding pocket identification}

For the proteins, especially NSP9 and ORF3a, which are dimeric and tetrameric with similar chain sequences, chain A was chosen for the study for simplicity. For SARS CoV-2 receptors, NSP9 and ORF3a, the binding pockets were predicted using SiteMap (Schrodinger). Residues in the active site pockets included mainly M13, Y33, G38, G39, R40, F41, V42, L43, F57, P58, K59, S60, I66, Y67, T68, E69, I92, K93, G94, L95 and N96, among others. The sequence region 94-97 is found to be rich in polar and hydrophobic residues (Sutton et al., 2004). The active site residues in ORF3a include mainly K75, F79, N82, Q116, S117, N119, F120, R122, I123, L127 and L139, among others. The second or third region is properly responsible for Golgi localization. The residues K75, F79 and N82, lie in the second transmembrane helix domain, while residues Q116, S117, N119, F120, R122 and I123 in the third transmembrane helix region (UniProtKB P0DTC3; https://www.uniprot.org/). For furin binding region, residues D153, H194, A252, S253, W254, P256, E257, N295, D301, E331, and S368 were obtained. Interleukin-6 contained four helices linked with loops (Somers et al., 1997). The C-terminal region (175-181) was found to be the receptor-binding domain with ARG179 as the key residue (Fontaine et al., 1993). A and $\mathrm{D}$ helices played vital roles in signal transduction and receptor binding. The degree to which amino acid residues will be conserved is highly dependent on the structural as well as functional significance. The ConSurf server used in this study estimated the same based on the phylogenetic relations between homologous sequences (Ashkenazy et al., 2016; Celniker et al., 2013; Ashkenazy et al., 2010), while PrankWeb uses the Jensen-Divergence method for calculating the conservation scores(Jendele et al., 2 019; Krivak et al., 2018). Figure 2 shows the 
surface distribution of conserved areas at the host receptors evaluated using ConSurf. The data received from PrankWeb verifies the same (Figure S2 in SI).

\section{In silico virtual screening}

Phytochemicals have also been reported to inhibit SARS-CoV-2 via a number of mechanisms (Ghildiyal et al., 2020; Gurung et al., 2020). Most phytochemicals like alkaloids, flavonoids, terpenoids, coumarins, and lignins inhibit the virus in the host due to their antioxidant activities, scavenging abilities, inhibition of DNA and RNA synthesis, or the blocking of viral reproduction (Naithani et al., 2010). Harnessing this potential of plant-based bioactives to speed up the much-desired development of COVID-19 therapeutics is strengthened by advances in computer-aided drug discovery (CADD) that deploys several computational technologies to the drug design process (Ebhohimen et al., 2020). This computational study identified promising phytochemicals from some of the reported antiviral and anti-inflammatory medicinal plants screened against SARS Cov-2 Nonstructural protein 9 (NSP9) RNA binding protein, and further scrutinizing the probable binding interactions it can have with other targets involved in COVID-19, including the open reading frame protein 3a (ORF3a) which is experimentally found to induce cellular apoptosis (Ren et al., 2020), furin convertase that activates the spike glycoprotein of SARS Cov-2 and interleukin-6, one among the many critical inflammatory cytokines that can significantly contribute to, fever, lymphopenia, coagulation, lung injury, and multi-organ failure (MOF) (Abbasifard et al., 2020). The compounds collected range from chemical classes, including flavonoids, terpenoids, polyphenolics, saponins, thiophenes, furyl compounds, alkaloids, coumarins, sulfides, to polysaccharides. The custom workflow options of Mcule make the virtual screening process easier for execution, and the cloud computing server facilitates faster processing for quick screening. To identify the potent phytochemicals, virtual hits from the in house generated library of 521 phytochemicals, from the first filter of the workflow, were checked for the total number of RO5 violations; a total of 452 molecules were found to have either two or fewer violations. According to the Lipinski Rule of Five (RO5), if a compound has a molecular weight $(\mathrm{Mw})>500 \mathrm{Da}$, calculated $\mathrm{M} \log \mathrm{P}>4.15$, hydrogen-bond donors $>5$, hydrogen-bond acceptors $>10$, it is unlikely to be further pursued as a potential drug, because it would perhaps lack properties that are necessary for its absorption, distribution, metabolism, and excretion (Lipinski et al., 1997). Traditionally, a prominent number of drugs that target viral receptors deviate from Lipinski's RO5 (Doak et al., 2017) and have now opened immense potentials for compounds beyond RO5 drug space. Hence, to increase the chemical discovery space, we kept the maximum number of RO5 violations to two for further narrowing down the library of molecules to the most relevant molecules for the receptors of our choice.

These drug-like compounds were further taken for the next workflow step of Vina docking. The Vina docking algorithm (Trott and Olson, 2010) is the most frequently used tool for docking because of its high precision and robustness. The returned result for each of the receptors after the screening was set to the top 30 molecules with the best docking scores. Docking scores of the resultant phytochemicals ranged from a value of -7.1 to $-9.1 \mathrm{kcal} / \mathrm{mol}$ for NSP9 (6W4B), -7.0 to $-8.5 \mathrm{kcal} / \mathrm{mol}$ for ORF3a protein $(6 \mathrm{XDC}),-6.9$ to $-8.1 \mathrm{kcal} / \mathrm{mol}$ for 
Interleukin-6 (1ALU) cytokine and -8.4 to $-9.6 \mathrm{kcal} / \mathrm{mol}$ for the furin convertase (5JXI). Based on the binding energies of the virtual hits, the cutoff values of docking scores were selected for all the four receptors for the identification of potential inhibitors. Vina docking was manually performed for known inhibitors of all the four target proteins. Table 3 enlists the docking scores for the inhibitors used against each of the receptors.

Table 3. Details of inhibitor chosen for each receptor and their docking scores upon binding with their respective receptors. The docking score threshold was set up for the receptors taking into consideration the highest score of the standard molecule and the range of docking scores of the top 30 retrieved molecules for all the receptors

\begin{tabular}{|c|c|c|c|c|}
\hline $\begin{array}{l}\text { Recepto } \\
\mathbf{r}\end{array}$ & Inhibitor & $\begin{array}{l}\text { Docking Score } \\
(\mathbf{k c a l} / \mathrm{mol})\end{array}$ & $\begin{array}{l}\text { Set Cut-off } \\
\text { (kcal/mol) }\end{array}$ & References \\
\hline \multirow[b]{2}{*}{ NSP9 } & Verdinexor & -7.7 & \multirow[b]{2}{*}{$\leq-7.8$} & \multirow[b]{2}{*}{ Gordon et al., 2020} \\
\hline & Dabrafenib & -6.8 & & \\
\hline \multirow[b]{2}{*}{ ORF3a } & Emodin & -6.9 & \multirow[b]{2}{*}{$\leq-7.1$} & \multirow{2}{*}{$\begin{array}{l}\text { Schwarz et al., 2011; } \\
\text { Adnan, } 2020\end{array}$} \\
\hline & Tranilast & -7.0 & & \\
\hline \multirow[b]{2}{*}{ IL-6 } & Madindoline A & -6.9 & \multirow[b]{2}{*}{-} & \multirow{2}{*}{$\begin{array}{l}\text { Hayashi et al., 2002; } \\
\text { Hong et al. } 2015\end{array}$} \\
\hline & LMT28 & -5.4 & & \\
\hline Furin & $\begin{array}{l}\text { Phenylacetyl arg-val-arg } \\
\text { 4-amidino benzylamide }\end{array}$ & -7.8 & - & Becker et al., 2010 \\
\hline
\end{tabular}

The docking scores of NSP9 against Verdinexor and Dabrafenib as inhibitors (Gordon et al., 2020) were found to be -7.7 and $-6.8 \mathrm{kcal} / \mathrm{mol}$, respectively. Therefore, particularly, based on Autodock Vina docking scores $(\Delta G)$ of the known inhibitors for NSP9, the cut off value was set as $\leq-7.8 \mathrm{kcal} / \mathrm{mol}$. Similarly, upon docking ORF3a, with two of its inhibitors Emodin and Tranilast (Schwarz et al., 2011; Adnan, 2020), the docking scores found were -6.9 and -7.0 $\mathrm{kcal} / \mathrm{mol}$, respectively. Hence a strict benchmark of binding affinity for the identification of potential Phyto ligands for ORF3a was set as $\leq-7.1 \mathrm{kcal} / \mathrm{mol}$. However, the docking scores of IL-6 and Furin with its inhibitor were far less than the maximum docking scores of the top 30 resultant molecules retrieved after screening. Hence, for Furin and IL-6, all the molecules were chosen for further analysis. While for the SARS CoV2 viral targets, cut-off values $\leq-7.8$ $\mathrm{kcal} / \mathrm{mol}$ for NSP9 RNA binding protein and $\leq-7.1 \mathrm{kcal} / \mathrm{mol}$ for ORF protein $3 \mathrm{a}$ obtained formed the basis for considering 6 and 23 compounds, respectively for further analysis. The top 6 ligands for NSP9 were further assessed for their MM-GBSA energy scores prior to the Molecular Dynamic simulation study. Table S3 (SI) contains the docking scores for all molecules that passed the docking thresholds for each of the receptors, along with the number of RO5 violations.

Of interest was how the top six phytochemicals, namely Ochnaflavone, Hispaglabridin B, Corylin, Glabrone, Licoflavone B, and Neoandrographolide, that passed the minimum cut off threshold for binding affinity scores for NSP9, performed for the three other target receptors 
that were chosen. Among these six potential phytochemicals, we found out that Ochnaflavone, Hispaglabridin B, and Licoflavone B passed the docking threshold for all other receptors. Also, Corylin was found to have passed the docking threshold for Furin and ORF3a, while Glabrone passed the docking threshold for Furin besides NSP9. Neoandrographolide was unique for the Nonstructural protein 9 and was not in the top 30 screened libraries for any of the other three receptors. A few other top NSP9 docked molecules were scrutinized, although they didn't pass the set threshold based on the standard drug chosen, but seemingly have good polypharmacological properties. Hispaglabridin A that had a binding affinity score of -7.7 $\mathrm{kcal} / \mathrm{mol}$ is possibly a potent inhibitor for the other three receptors since it passed the threshold for ORF3a, Furin, and IL-6 with docking scores -7.3, -9.2, and -7.1 kcal/mol, respectively. Psoralidin, which had a binding affinity value of $-7.6 \mathrm{kcal} / \mathrm{mol}$ for NSP9, was found to have a docking score of $-8.1 \mathrm{kcal} / \mathrm{mol}$ against IL-6 and $-9.0 \mathrm{kcal} / \mathrm{mol}$ against Furin. Licoflavone A, Licoflavonone, Kanzonol U, Hydnocarpin, and Glabrol are among the others that have promising affinity values for multiple targets.

\section{Pharmacokinetics and ADMET screening}

Pharmacokinetic properties of drugs usually refer to the properties defining the movement of the drug into, through, and out of the body. Pharmacokinetics can simply be defined as the variation in drug concentration with time due to several processes involved in the absorption, distribution, metabolism, and excretion. Adverse drug reactions in the body mainly depend on patient-related factors (like renal function, genetic makeup, sex, age), and on the physicochemical properties of the drug, so is pharmacokinetics (Alomar, 2014). Pharmacokinetic properties of the compounds need to be identified before performing in vitro and in vivo studies. Additionally, the behavioral action of compounds inside host organisms needs to be ascertained in terms of its rate of absorption and excretion, metabolism, and distribution. Prediction of the drug ADME properties at the early stages of the drug discovery pipeline not only helps in removing the compounds that have poor ADMET properties, but it also helps in reducing research and development costs. The physicochemical properties of the molecules were obtained from the Mcule server, and admetSAR was used to get the ADMET properties for the drugs that met the threshold docking score. Table 4 displays the results for all the computed molecules. With the exception of Ononin and Calycosin 7-o-glucoside, all the potential ligand hits possessed human gastrointestinal absorption, while not many of them possessed blood-brain permeance capability. 
Table 4 ADMET parameters for screening the lead compounds. HIA-Human Intestinal Absorption; BBB-Blood Brain Barrier Penetration; P-gp-Phospho glycoprotein; CYP2D6-Cytochrome p450 2D6; [Phytochemicals labeled in green are the ones that do not possess P-gp substrate binding, CYP2D6 Inhibition, Carcinogenicity and AMES Mutagenicity]

\begin{tabular}{|c|c|c|c|c|c|c|c|c|}
\hline $\begin{array}{c}\text { Recepto } \\
\mathbf{r}\end{array}$ & $\begin{array}{c}\text { Ligand } \\
\text { (PubChemI } \\
\text { D) }\end{array}$ & Phytochemical & $\begin{array}{c}\mathrm{HI} \\
\mathrm{A}\end{array}$ & $\begin{array}{c}\text { BB } \\
\text { B }\end{array}$ & $\begin{array}{c}\text { P-gp } \\
\text { Substrat } \\
\text { e }\end{array}$ & $\begin{array}{l}\text { CYP2D6 } \\
\text { Inhibitio } \\
\mathbf{n}\end{array}$ & \begin{tabular}{|c} 
Carcinogenicit \\
y (binary)
\end{tabular} & \begin{tabular}{|c|} 
AMES \\
Mutagenesi \\
$\mathrm{s}$ \\
\end{tabular} \\
\hline \multirow[b]{6}{*}{ NSP9 } & 5492110 & Ochnaflavone & Y & $\mathrm{N}$ & $\mathrm{N}$ & $\mathrm{N}$ & $\mathrm{N}$ & $\mathrm{N}$ \\
\hline & 15228661 & Hispaglabridin B & $\mathrm{Y}$ & $\mathrm{Y}$ & Y & $\mathrm{N}$ & $\mathrm{N}$ & Y \\
\hline & 5316097 & Corylin & Y & Y & $\mathrm{N}$ & $\mathrm{N}$ & $\mathrm{N}$ & $\mathrm{N}$ \\
\hline & 5317652 & Glabrone & Y & $\mathrm{N}$ & $\mathrm{N}$ & $\mathrm{N}$ & $\mathrm{N}$ & $\mathrm{N}$ \\
\hline & 11349817 & Licoflavone B & Y & $\mathrm{N}$ & $\mathrm{N}$ & $\mathrm{N}$ & $\mathrm{N}$ & $\mathrm{N}$ \\
\hline & 9848024 & $\begin{array}{c}\text { Neoandrographoli } \\
\text { de }\end{array}$ & Y & $\mathrm{N}$ & $\mathrm{N}$ & $\mathrm{N}$ & $\mathrm{N}$ & $\mathrm{N}$ \\
\hline & 5492110 & Ochnaflavone & Y & $\mathrm{N}$ & $\mathrm{N}$ & $\mathrm{N}$ & $\mathrm{N}$ & $\mathrm{N}$ \\
\hline & 15228661 & Hispaglabridin B & Y & $\mathrm{Y}$ & Y & $\mathrm{N}$ & $\mathrm{N}$ & Y \\
\hline & 11349817 & Licoflavone B & Y & $\mathrm{N}$ & $\mathrm{N}$ & $\mathrm{N}$ & $\mathrm{N}$ & $\mathrm{N}$ \\
\hline & 11597485 & Glychonide A & Y & $\mathrm{N}$ & $\mathrm{N}$ & $\mathrm{N}$ & $\mathrm{N}$ & $\mathrm{N}$ \\
\hline & 11596309 & Glabrol & Y & $\mathrm{N}$ & $\mathrm{N}$ & $\mathrm{N}$ & $\mathrm{N}$ & $\mathrm{N}$ \\
\hline & 11016019 & \begin{tabular}{|} 
Diosmetin \\
7-o-beta-D-glucopy \\
ranoside
\end{tabular} & Y & $\mathrm{N}$ & $\mathrm{N}$ & $\mathrm{N}$ & $\mathrm{N}$ & $\mathrm{N}$ \\
\hline & 5281377 & Genistin & Y & $\mathrm{N}$ & $\mathrm{N}$ & $\mathrm{N}$ & $\mathrm{N}$ & $\mathrm{N}$ \\
\hline & 5316097 & Corylin & Y & $\mathrm{Y}$ & $\mathrm{N}$ & $\mathrm{N}$ & $\mathrm{N}$ & $\mathrm{N}$ \\
\hline & 503737 & Liquiritin & Y & $\mathrm{N}$ & $\mathrm{N}$ & $\mathrm{N}$ & $\mathrm{N}$ & $\mathrm{N}$ \\
\hline & 14218027 & Licoflavonone & Y & $\mathrm{N}$ & $\mathrm{N}$ & $\mathrm{N}$ & $\mathrm{N}$ & $\mathrm{N}$ \\
\hline & 259846 & Lupeol & Y & $\mathrm{Y}$ & $\mathrm{N}$ & $\mathrm{N}$ & $\mathrm{N}$ & $\mathrm{N}$ \\
\hline & 72326 & Betulin & $\mathrm{Y}$ & $\mathrm{N}$ & $\mathrm{N}$ & $\mathrm{N}$ & $\mathrm{N}$ & $\mathrm{N}$ \\
\hline & 442774 & Hispaglabridin A & Y & $\mathrm{Y}$ & Y & $\mathrm{N}$ & $\mathrm{N}$ & $\mathrm{Y}$ \\
\hline & 10337211 & Bavachinin & Y & $\mathrm{N}$ & $\mathrm{N}$ & $\mathrm{N}$ & $\mathrm{N}$ & $\mathrm{N}$ \\
\hline & 14236566 & Bavachin & Y & $\mathrm{N}$ & $\mathrm{N}$ & $\mathrm{N}$ & $\mathrm{N}$ & $\mathrm{N}$ \\
\hline ORF3a & 5320053 & Neobabaisoflavone & Y & $\mathrm{N}$ & $\mathrm{N}$ & $\mathrm{N}$ & $\mathrm{N}$ & $\mathrm{N}$ \\
\hline
\end{tabular}




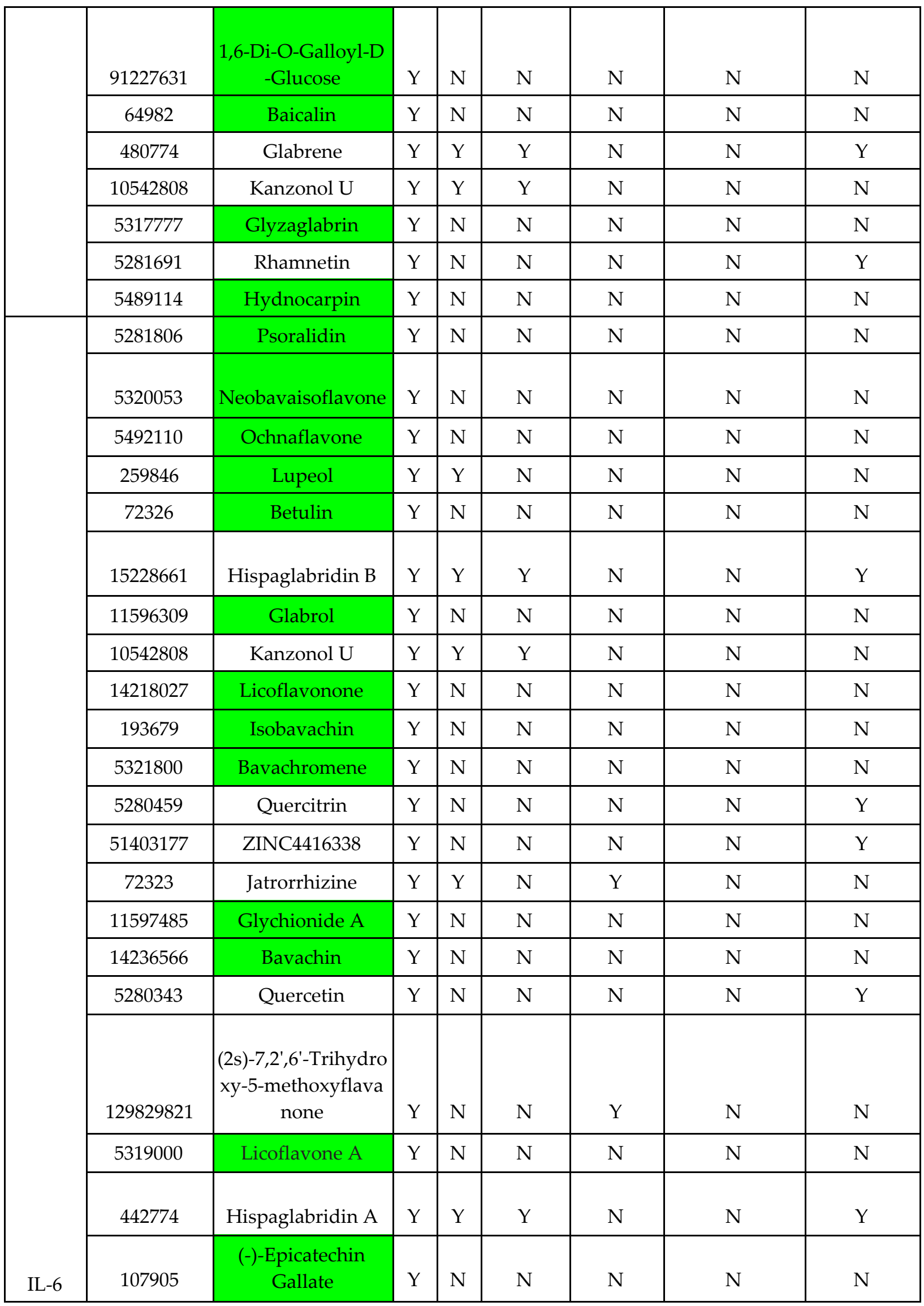




\begin{tabular}{|c|c|c|c|c|c|c|c|c|}
\hline & 11349817 & Licoflavone B & Y & $\mathrm{N}$ & $\mathrm{N}$ & $\mathrm{N}$ & $\mathrm{N}$ & $\mathrm{N}$ \\
\hline & 442813 & Ononin & $\mathrm{N}$ & $\mathrm{N}$ & $\mathrm{N}$ & $\mathrm{N}$ & $\mathrm{N}$ & $\mathrm{N}$ \\
\hline & 5316733 & Dihydrooroxylin A & $\mathrm{Y}$ & Y & $\mathrm{N}$ & $\mathrm{N}$ & $\mathrm{N}$ & $\mathrm{Y}$ \\
\hline & 5281605 & Baicalein & $\mathrm{Y}$ & $\mathrm{N}$ & $\mathrm{N}$ & $\mathrm{N}$ & $\mathrm{N}$ & $\mathrm{N}$ \\
\hline & 5280666 & Chrysoeriol & $\mathrm{Y}$ & $\mathrm{N}$ & $\mathrm{N}$ & $\mathrm{N}$ & $\mathrm{N}$ & $\mathrm{N}$ \\
\hline & 440735 & Eriodictyol & $\mathrm{Y}$ & $\mathrm{N}$ & $\mathrm{N}$ & $\mathrm{N}$ & $\mathrm{N}$ & $\mathrm{Y}$ \\
\hline & 46893290 & ZINC14728438 & $\mathrm{Y}$ & $\mathrm{N}$ & $\mathrm{N}$ & $\mathrm{Y}$ & $\mathrm{N}$ & $\mathrm{N}$ \\
\hline & 5322076 & $\begin{array}{l}\text { 5,7,2'-Trihydroxy-6 } \\
\text {-Methoxyflavone }\end{array}$ & Y & $\mathrm{N}$ & $\mathrm{N}$ & $\mathrm{N}$ & $\mathrm{N}$ & $\mathrm{N}$ \\
\hline & 392443 & Licoisoflavanone & $\mathrm{Y}$ & $\mathrm{Y}$ & $\mathrm{N}$ & $\mathrm{N}$ & $\mathrm{N}$ & $\mathrm{Y}$ \\
\hline & 107905 & $\begin{array}{l}\text { (-)-Epicatechin } \\
\text { Gallate }\end{array}$ & Y & $\mathrm{N}$ & $\mathrm{N}$ & $\mathrm{N}$ & $\mathrm{N}$ & $\mathrm{N}$ \\
\hline & 11349817 & Licoflavone B & $\mathrm{Y}$ & $\mathrm{N}$ & $\mathrm{N}$ & $\mathrm{N}$ & $\mathrm{N}$ & $\mathrm{N}$ \\
\hline & 65064 & EGCG & $\mathrm{Y}$ & $\mathrm{N}$ & $\mathrm{N}$ & $\mathrm{N}$ & $\mathrm{N}$ & $\mathrm{N}$ \\
\hline & 91227631 & $\begin{array}{c}1,6 \\
\text { di-o-galloyl-d-gluc } \\
\text { ose }\end{array}$ & Y & $\mathrm{N}$ & $\mathrm{N}$ & $\mathrm{N}$ & $\mathrm{N}$ & $\mathrm{N}$ \\
\hline & 442774 & Hispaglabridin A & Y & Y & $\mathrm{Y}$ & $\mathrm{N}$ & $\mathrm{N}$ & $\mathrm{Y}$ \\
\hline & 5318267 & $\begin{array}{c}\text { Calycosin } \\
\text { 7-o-glucoside }\end{array}$ & $\mathrm{N}$ & $\mathrm{N}$ & $\mathrm{N}$ & $\mathrm{N}$ & $\mathrm{N}$ & $\mathrm{N}$ \\
\hline & 5281806 & Psoralidin & Y & $\mathrm{N}$ & $\mathrm{N}$ & $\mathrm{N}$ & $\mathrm{N}$ & $\mathrm{N}$ \\
\hline & 5281855 & Ellagic Acid & $\mathrm{Y}$ & $\mathrm{N}$ & $\mathrm{N}$ & $\mathrm{N}$ & $\mathrm{N}$ & $\mathrm{N}$ \\
\hline & 5492110 & Ochnaflavone & $\mathrm{Y}$ & $\mathrm{N}$ & $\mathrm{N}$ & $\mathrm{N}$ & $\mathrm{N}$ & $\mathrm{N}$ \\
\hline \multirow[b]{7}{*}{ Furin } & 14135325 & Dihydrobaicalin & $\mathrm{Y}$ & $\mathrm{N}$ & $\mathrm{N}$ & $\mathrm{N}$ & $\mathrm{N}$ & $\mathrm{N}$ \\
\hline & 64982 & Baicalin & Y & $\mathrm{N}$ & $\mathrm{N}$ & $\mathrm{N}$ & $\mathrm{N}$ & $\mathrm{N}$ \\
\hline & 11221431 & $\begin{array}{c}\text { Glabroisoflavanone } \\
\text { A }\end{array}$ & $\mathrm{Y}$ & Y & Y & $\mathrm{N}$ & $\mathrm{N}$ & $\mathrm{Y}$ \\
\hline & 343585 & $\begin{array}{c}\text { Isoandrographolid } \\
\mathrm{e}\end{array}$ & Y & $\mathrm{Y}$ & $\mathrm{N}$ & $\mathrm{N}$ & $\mathrm{N}$ & $\mathrm{N}$ \\
\hline & 5280637 & Cynaroside & $\mathrm{Y}$ & $\mathrm{N}$ & $\mathrm{N}$ & $\mathrm{N}$ & $\mathrm{N}$ & $\mathrm{Y}$ \\
\hline & 11597485 & Glychionide A & Y & $\mathrm{N}$ & $\mathrm{N}$ & $\mathrm{N}$ & $\mathrm{N}$ & $\mathrm{N}$ \\
\hline & 193679 & Isobavachin & Y & $\mathrm{N}$ & $\mathrm{N}$ & $\mathrm{N}$ & $\mathrm{N}$ & $\mathrm{N}$ \\
\hline
\end{tabular}




\begin{tabular}{|c|c|c|c|c|c|c|c|c|}
\hline 14218027 & Licoflavanone & $\mathrm{Y}$ & $\mathrm{N}$ & $\mathrm{N}$ & $\mathrm{N}$ & $\mathrm{N}$ & $\mathrm{N}$ \\
\hline 5489114 & Hydnocarpin & $\mathrm{Y}$ & $\mathrm{N}$ & $\mathrm{N}$ & $\mathrm{N}$ & $\mathrm{N}$ & $\mathrm{N}$ \\
\hline 5316097 & Corylin & $\mathrm{Y}$ & $\mathrm{Y}$ & $\mathrm{N}$ & $\mathrm{N}$ & $\mathrm{N}$ & $\mathrm{N}$ \\
\hline 5317652 & Glabrone & $\mathrm{Y}$ & $\mathrm{N}$ & $\mathrm{N}$ & $\mathrm{N}$ & $\mathrm{N}$ & $\mathrm{N}$ \\
\hline & & & & & & & $\mathrm{N}$ & $\mathrm{Y}$ \\
\hline & & & $\mathrm{N}$ & $\mathrm{N}$ & $\mathrm{N}$ \\
\hline 5228661 & Hispaglabridin B & $\mathrm{Y}$ & $\mathrm{Y}$ & $\mathrm{Y}$ & $\mathrm{N}$ & $\mathrm{N}$ & $\mathrm{N}$ \\
\hline 5281675 & Liquiritin & $\mathrm{Y}$ & $\mathrm{N}$ & $\mathrm{N}$ & $\mathrm{N}$ & $\mathrm{N}$ & $\mathrm{N}$ \\
\hline 5280445 & Luteolin & $\mathrm{Y}$ & $\mathrm{N}$ & $\mathrm{N}$ & $\mathrm{N}$ & $\mathrm{N}$ & $\mathrm{N}$ \\
\hline 5281605 & Baicalein & $\mathrm{Y}$ & $\mathrm{N}$ & $\mathrm{N}$ & $\mathrm{N}$ & $\mathrm{N}$ & $\mathrm{N}$ \\
\hline 5321800 & Bavachromene & $\mathrm{Y}$ & $\mathrm{N}$ & $\mathrm{N}$ & $\mathrm{N}$ & $\mathrm{N}$ & $\mathrm{N}$ \\
\hline 71308174 & Chebulic Acid & $\mathrm{Y}$ & $\mathrm{N}$ & $\mathrm{N}$ & $\mathrm{N}$ & $\mathrm{N}$ & $\mathrm{N}$ \\
\hline 5281607 & Chrysin & $\mathrm{Y}$ & $\mathrm{N}$ & $\mathrm{N}$ & $\mathrm{N}$ & $\mathrm{N}$ & $\mathrm{N}$ \\
\hline
\end{tabular}

As the final step to filter potential inhibitors for the targets chosen, among many properties, there was extensive focus on the phosphoglycoprotein (Pgp) substrate binding, cytochrome p450 (CYP2D6) inhibition, carcinogenicity, and AMES mutagenicity to filter out the potential inhibitors for the receptors of our study. In general, cytochrome P4502D6 plays a fundamental role in drug metabolism, involved in the metabolism of a variety of liver substrates (Lynch and Price, 2007). Major cases of drug-drug interactions occur due to its inhibition by any medication. Pgp is an ATP dependent efflux transporter glycoprotein, which reduces the efficacy of drugs that are p-gp substrates (Finch and Pillans, 2014). Interestingly, except for Hispaglabridin B, all the top virtual hits of NSP9 are noncarcinogenic, non AMES mutagenic, non inhibitor of CYP2D6 and are not pgp substrate either, and hence were chosen as the final leads for NSP9. Table 5 depicts the respective plant sources, geographical locations, and compound classes for the 5 final leads of NSP9, and their 2D structures (retrieved from PubChem) are demonstrated in Figure 6. Upon further filtering, the compounds for ORF3a, Furin, and IL-6 targets, 18, 23 and 19 final potential lead compounds were found for each of the receptors, respectively. As a side note, we must not also forget that development in drug discovery research has been successful in manipulating some of the functionalities to modify ADMET properties for efficient lead optimization. Small tweakings in the molecular structures can result in remarkable property manipulations. 
Polypharmacology of some medicinal plant metabolites against SARS-CoV-2 and host targets: Molecular dynamics evaluation of NSP9 RNA binding protein

Table 5.. Potential plant metabolite inhibitor for NSP 9 and their respective plant sources, geographical locations and compound classes

\begin{tabular}{|l|l|l|l|l|l|}
\hline S/N & $\begin{array}{l}\text { COMPOUND } \\
\text { NAME }\end{array}$ & $\begin{array}{l}\text { BOTANICAL } \\
\text { NAME }\end{array}$ & FAMILY & $\begin{array}{l}\text { Compoun } \\
\text { d Class }\end{array}$ & $\begin{array}{l}\text { Geographical } \\
\text { Location }\end{array}$ \\
\hline 1 & Ochnaflavone & Lonicera japonica & $\begin{array}{l}\text { Caprifoliacea } \\
\text { e }\end{array}$ & $\begin{array}{l}\text { Biflavonoi } \\
\text { d }\end{array}$ & $\begin{array}{l}\text { China, Japan, } \\
\text { Korea, East Asian. }\end{array}$ \\
\hline 2 & Hispaglabridin B & $\begin{array}{l}\text { Glycyrrhiza } \\
\text { glabra }\end{array}$ & Fabaceae & Flavonoids & $\begin{array}{l}\text { Spain, Italy, Turkey, } \\
\text { Central Asia. }\end{array}$ \\
\hline 3 & Corylin & $\begin{array}{l}\text { Psoraleae } \\
\text { corylifolia }\end{array}$ & Fabaceae & Flavonoids & $\begin{array}{l}\text { Western part of } \\
\text { China }\end{array}$ \\
\hline 5 & Glabrone & $\begin{array}{l}\text { Glycyrrhiza } \\
\text { glabra }\end{array}$ & Fabaceae & Flavonoids & $\begin{array}{l}\text { Spain, Italy, Turkey, } \\
\text { Central Asia. }\end{array}$ \\
\hline 6 & Licoflavone B & $\begin{array}{l}\text { Glycyrrhiza } \\
\text { glabra }\end{array}$ & Fabaceae & Flavonoids & $\begin{array}{l}\text { Spain, Italy, Turkey, } \\
\text { Central Asia. }\end{array}$ \\
\hline
\end{tabular}




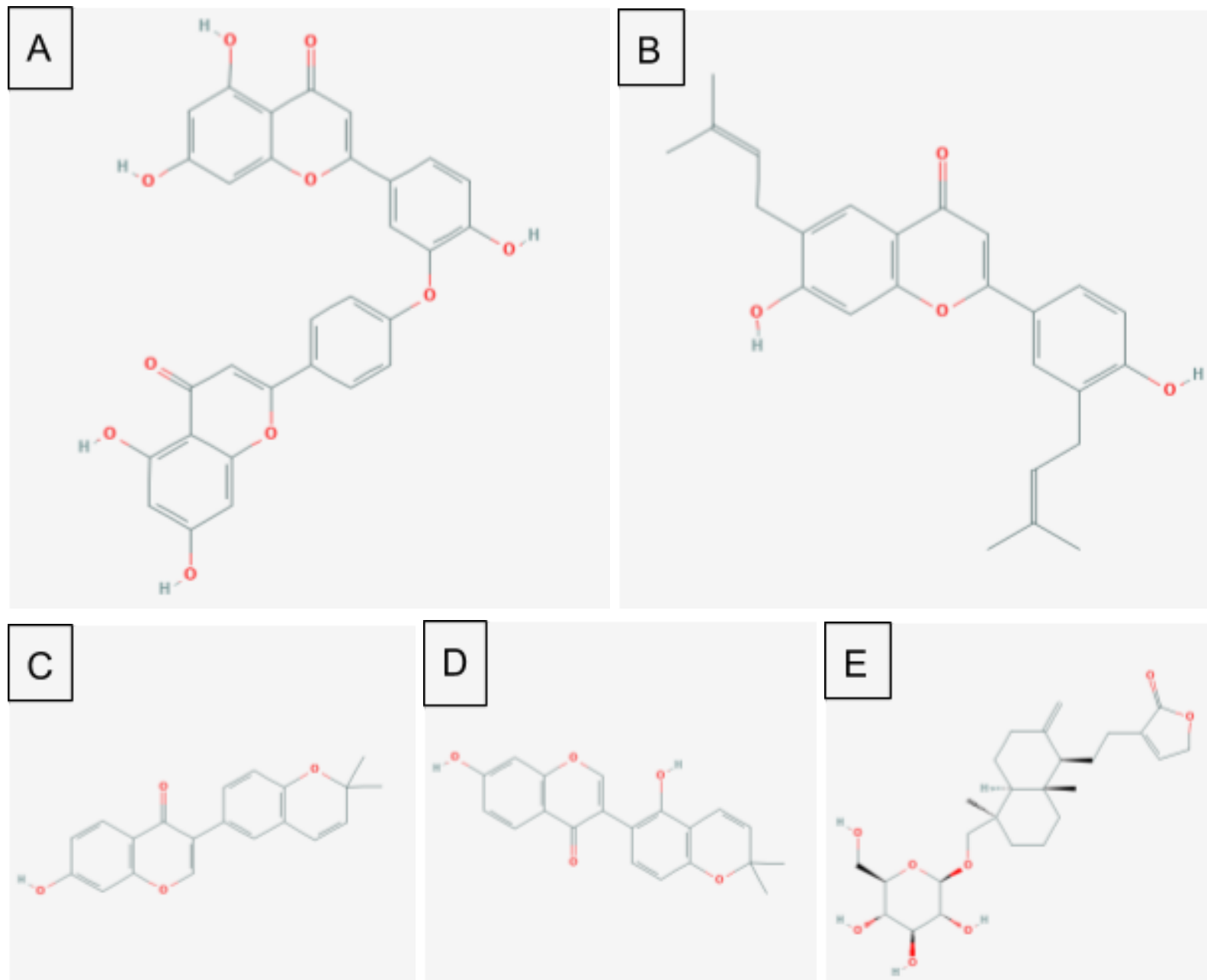

Figure 6. Lead compounds for NSP9 (A)Ochnaflavone,(B) Licoflavone B, (C) Corylin, (D) Glabrone,(E) Neo-andrographolide

\section{RAT Acute toxicity assessment}

Acute toxicity is an adverse effect that occurs after single or multiple exposures to a substance, usually within 24 hours. Thus the knowledge of the rodent acute toxicity of lead compounds is essential in drug design. The prediction of the chosen ligand's acute toxicity was performed using a free web server, GUSAR (Lagunin et al., 2011), which considers various routes of drug administration (subcutaneous, oral, inhalation, intravenous and intraperitoneal). LD50 values correspond to acute toxicity dose that leads to $50 \%$ mortality in 24 hours after administration of substance. Acute toxicity determined by inhalation or oral administration is pertinent for assessing overall toxicological risk, whereas that for intravenous is important for drug development (Polish et al. 2019). Rat acute toxicity evaluation was carried out for the five leads of NSP9 (including Hispaglabridin B), which presumably possess polypharmacological properties. Despite Hispaglabridin B failing the ADMET tests, it's predicted LD50 was analysed hence, its inclusion here too. The results of the rodent acute toxicity presented in Table 6 shows that the chosen ligands - Licoflavone B, Ochnaflavone, Corylin, and Glabrone 
can be considered to be low toxicity drugs (class 4 and 5). Ochnaflavone was non-toxic in intraperitoneal and subcutaneous routes of administration. However, Hispaglabridin B was observed to be of class 3 toxicity in oral administration. This also shows evidence for further experimental preclinical studies for the molecules as lead compounds for the treatment of COVID-19.

Table 6. In silico prediction of acute toxicity in rodent models and chemical classification of selected phyto ligands with promising ADMET properties.

\begin{tabular}{|c|c|c|c|c|c|c|c|c|}
\hline \multirow[b]{2}{*}{ Compound } & \multicolumn{2}{|l|}{ Rat IP* } & \multicolumn{2}{|c|}{ Rat IV* } & \multicolumn{2}{|c|}{ Rat Oral* } & \multicolumn{2}{|l|}{ Rat SC* } \\
\hline & $\begin{array}{l}\text { LD50 } \\
(\mathrm{mg} / \mathrm{kg} \\
)\end{array}$ & $\begin{array}{l}\text { LD50 } \\
\text { Classificatio } \\
n\end{array}$ & $\begin{array}{l}\text { LD50 } \\
(\mathrm{mg} / \mathrm{k} \\
\mathrm{g})\end{array}$ & $\begin{array}{l}\text { LD50 } \\
\text { Classificatio } \\
\text { n }\end{array}$ & $\begin{array}{l}\text { LD50 } \\
(\mathrm{mg} / \mathrm{kg}\end{array}$ & $\begin{array}{l}\text { LD50 } \\
\text { Classificatio } \\
n\end{array}$ & $\begin{array}{l}\text { LD50 } \\
(\mathrm{mg} / \mathrm{kg} \\
)\end{array}$ & $\begin{array}{l}\text { LD50 } \\
\text { Classificatio } \\
n\end{array}$ \\
\hline $\begin{array}{l}\text { Hispaglabridi } \\
\text { n B }\end{array}$ & $\begin{array}{l}432,800 \\
\text { in } \mathrm{AD}\end{array}$ & $\begin{array}{l}\text { Class } 4 \text { in } \\
\mathrm{AD}\end{array}$ & $\begin{array}{l}61,130 \\
\text { in } \mathrm{AD}\end{array}$ & $\begin{array}{l}\text { Class } 4 \text { in } \\
\mathrm{AD}\end{array}$ & $\begin{array}{l}114,500 \\
\text { in AD }\end{array}$ & $\begin{array}{l}\text { Class } 3 \text { in } \\
\mathrm{AD}\end{array}$ & $\begin{array}{l}347,800 \\
\text { in } \mathrm{AD}\end{array}$ & $\begin{array}{l}\text { Class } 4 \text { in } \\
\mathrm{AD}\end{array}$ \\
\hline Licoflavone B & $\mid \begin{array}{l}914,200 \\
\text { in } A D\end{array}$ & $\begin{array}{l}\text { Class } 5 \text { in } \\
A D\end{array}$ & $\begin{array}{l}276,10 \\
0 \text { in } \\
A D\end{array}$ & $\begin{array}{l}\text { Class } 4 \text { in } \\
\mathrm{AD}\end{array}$ & $\begin{array}{l}906,500 \\
\text { in } \mathrm{AD}\end{array}$ & $\begin{array}{l}\text { Class } 4 \text { in } \\
\text { AD }\end{array}$ & $\begin{array}{l}1866,00 \\
0 \text { in } \mathrm{AD}\end{array}$ & $\begin{array}{l}\text { Class } 5 \text { in } \\
\text { AD }\end{array}$ \\
\hline $\begin{array}{l}\text { Ochnaflavon } \\
\text { e }\end{array}$ & $\begin{array}{l}2065,00 \\
0 \text { in } A D\end{array}$ & $\mid \begin{array}{l}\text { Non Toxic in } \\
\mathrm{AD}\end{array}$ & $\begin{array}{l}459,00 \\
0 \text { in } \\
\mathrm{AD}\end{array}$ & $\begin{array}{l}\text { Class } 5 \text { in } \\
\mathrm{AD}\end{array}$ & $\begin{array}{l}2218,00 \\
0 \text { in } A D\end{array}$ & $\begin{array}{l}\text { Class } 5 \text { in } \\
\mathrm{AD}\end{array}$ & $\begin{array}{l}7027,00 \\
0 \text { in } \mathrm{AD}\end{array}$ & $\mid \begin{array}{l}\text { Non Toxic in } \\
\mathrm{AD}\end{array}$ \\
\hline Corylin & $\begin{array}{l}976,800 \\
\text { in } \mathrm{AD}\end{array}$ & $\begin{array}{l}\text { Class } 5 \text { in } \\
\mathrm{AD}\end{array}$ & $\begin{array}{l}155,60 \\
0 \text { in } \\
A D\end{array}$ & $\begin{array}{l}\text { Class } 4 \text { in } \\
\mathrm{AD}\end{array}$ & $\begin{array}{l}663,300 \\
\text { in } A D\end{array}$ & $\begin{array}{l}\text { Class } 4 \text { in } \\
\mathrm{AD}\end{array}$ & $\begin{array}{l}1479,00 \\
0 \text { in } \mathrm{AD}\end{array}$ & $\begin{array}{l}\text { Class } 5 \text { in } \\
\mathrm{AD}\end{array}$ \\
\hline Glabrone & $\begin{array}{l}913,900 \\
\text { in } \mathrm{AD}\end{array}$ & $\begin{array}{l}\text { Class } 5 \text { in } \\
\mathrm{AD}\end{array}$ & $\begin{array}{l}188,80 \\
0 \text { in } \\
\mathrm{AD}\end{array}$ & $\begin{array}{l}\text { Class } 4 \text { in } \\
\mathrm{AD}\end{array}$ & $\begin{array}{l}512,200 \\
\text { in } \mathrm{AD}\end{array}$ & $\begin{array}{l}\text { Class } 4 \text { in } \\
\mathrm{AD}\end{array}$ & $\begin{array}{l}1580,00 \\
0 \text { in } \mathrm{AD}\end{array}$ & $\begin{array}{l}\text { Class } 5 \text { in } \\
\mathrm{AD}\end{array}$ \\
\hline
\end{tabular}

*IP - Intraperitoneal route of administration, IV - Intravenous route of administration, Oral - Oral route of administration, SC - Subcutaneous route of administration, in AD - compound falls in applicability domain of models, out of AD - compound is out of applicability domain of models

\section{Binding interactions with NSP9}

We identified various non-covalent interactions of the ligands with the amino acid residues of the binding pocket of NSP9, namely H-bonding, Vanderwaals, pi-pi T shaped, pi-pi stacked, pi-sulfur, pi-sigma, alkyl, pi-alkyl, carbon-hydrogen and pi-donor hydrogen bonds. Table S4 (SI) lists all the existing interactions between ligands and NSP9 active site residues for the ligand-receptor poses. The best ranked lead molecule, Ochnaflavone, interacted with the binding site of the target with a binding affinity of $-9.1 \mathrm{kcal} / \mathrm{mol}$. This interaction is strengthened by two hydrogen bonds with GLY94 and ARG40 with bond lengths $2.29 \AA$ and $2.11 \AA$ respectively, Vander waals interaction with the residues THR68, ILE92, GLY 39, GLY38, PHE57, LYS59, MET13, LYS93, LEU95, SER60 of the binding pocket, a pi-pi interaction with PHE41 and alkyl, and pi-alkyl interactions with VAL42, ILE66, and ARG40. Among the other lead molecules that establish hydrogen bonding with pocket residues include Glabrone (with ARG40: bond length $2.42 \AA$ ) and Neo-andrographolide (with LYS93 AND PRO58: bond 
lengths $2.60 \AA$ and $2.31 \AA$, respectively). Figure 7 shows the NSP9-lead compounds binding interactions (including Hispaglabridin B).
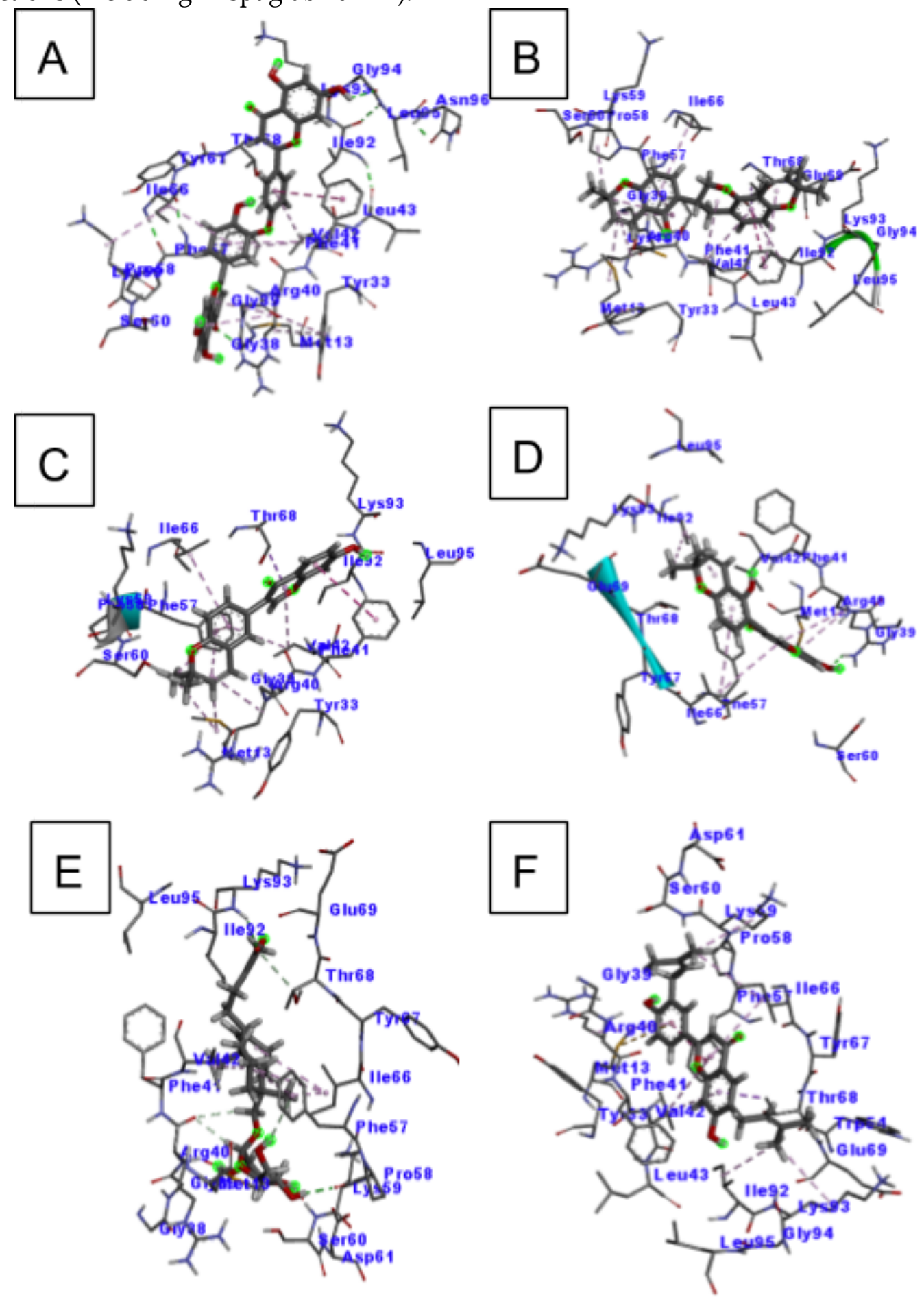

Figure 7. Protein-ligand interactions of the top-scoring phytochemical inhibitors with NSP9. NSP9 residues interacting with the ligand atoms via hydrogen bonds, $\pi$-interaction with alkyl or sulphur, Van der waals, hydrophobic bonds are labelled with the corresponding three-letter residue code along with their position in the protein sequence. The hydrogen bonds, $\pi-\pi$ interaction, pi-sulfur, alkyl interactions, and van der waals are displayed using green, magenta, yellow, pink, and cyan dotted lines, respectively. Images show NSP9 complexed 
with (A) Ochnaflavone, (B) Hispaglabridin B, (C) Corylin, (D) Glabrone, (E) Neoandrographolide, (F) Licoflavone $\mathrm{B}$,

Corylin and Licoflavone B develop a pi-sigma interaction with THR68, while Neo-andrographolide interacts with the same via pi-donor hydrogen bond. The interaction of Neo-andrographolide is also interesting because there is a possible interaction with PHE57 and ARG40 via carbon-hydrogen bonds. Glabrone and Licoflavone B are observed to interact by a pi-sulfur bond with MET13. Alkyl interactions with ILE66 and VAL42 are prominent in all the ligands. Among all the pocket residues, it seems LYS93, MET13, ARG40, VAL42, PHE57, ILE66, and THR68 play vital role in strengthening the bonds between the ligands and the receptor.

\section{Interactions of the polypharmacological leads with ORF3a, Furin and IL-6}

We evaluated the binding interactions of the target receptors with the two compounds, Ochnaflavone, and Licoflavone B, that took our interest due to their potential multi-target inhibition properties, promising ADMET properties, and RAT acute toxicity results. Figure 8 shows the 2D representation of all the different kinds of interactions that occur between the ligands and IL6, furin, and ORF3a. We found that Ochnaflavone established prominent hydrogen bonds with the residues present in the binding pockets for all the three targets besides NSP9. At the same time, Licoflavone B was seen to form hydrogen bonding interactions just with the residues of Furin. Apart from hydrogen bonds, the major contributions of the interaction of Ochnaflavone comes from pi-alkyl, pi-pi $\mathrm{T}$ shaped and stacked, and van der waals interaction with nearby residues. Licoflavone $B$ was seen to establish pi-sigma, pi-anion/cation, alkyl, and pi-alkyl, pi-pi T shaped and stacked, and van der waals interaction with the surrounding residue. Ochnaflavone interacted via hydrogen bonding with ASP301 and via van der waals interaction with GLU331, two key residues of the active site. Licoflavone B interacted with SER176 and ARG179 (one of the most critical active residues of IL-6) via van der waals interaction. Ochnaflavone established pi-alkyl interactions with LEU178 and ARG182, besides having van der waals interaction with ARG179. Both Ochnaflavone and Licoflavone B are observed to develop strong bonding interactions (as is shown in Figure 8) with the amino acid residues of the second and third transmembrane helix domain that plays an important role in the Golgi localisation. 


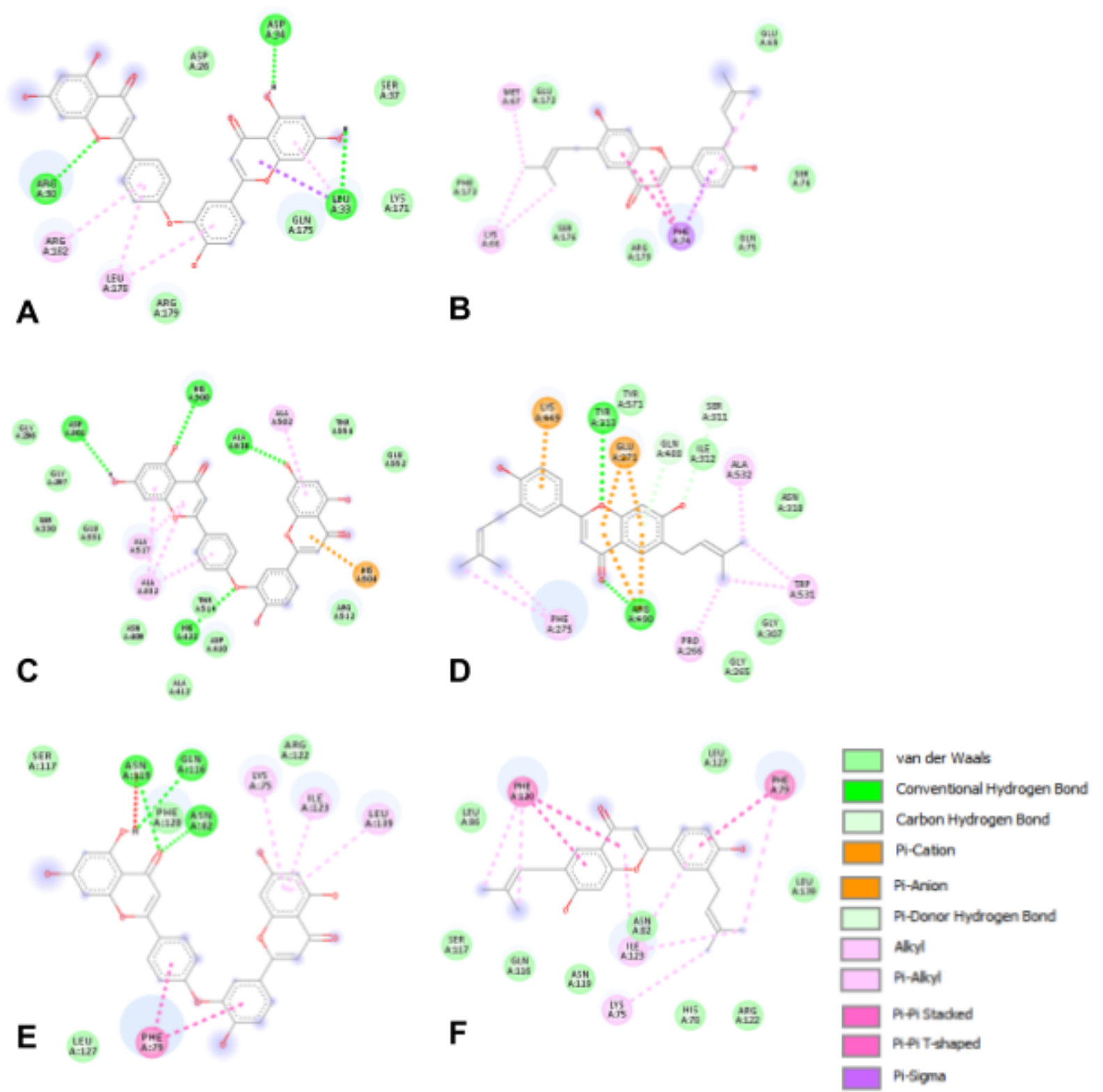

Figure 8. 2D representation of the interactions between ligands and the receptors ORF3a, Furin and IL-6; (A) Ochnaflavone and IL-6 (B) Licoflavone B and IL-6 (C) Ochnaflavone and Furin (D) Licoflavone B and Furin (E) Ochnaflavone and ORF3a (F) Licoflavone B and ORF3a

\section{Binding site analysis}

Besides analysing the binding interactions of the ligands with the amino acid residues in the pocket site, the physicochemical nature of the binding site was examined, and the spread in the aromaticity, solvent accessibility, hydrophobicity, and distribution of H-bond donor/acceptor sites across the surface of the binding site were evaluated. Figure 9 gives the representation of the distribution of the mentioned properties. It was observed that for ORF3a, which becomes membrane protein in its biochemical pathway, the binding site is highly solvent accessible and is dominated by hydrophobic regions, as is for the case of NSP9. IL-6 binding region does not possess aromaticity. However, furin and interleukin-6 were both dominated by hydrophilic 
regions (Figure S5 in SI). H-bond donor/acceptor sites were approximately equally distributed throughout the binding region for all the four receptors.
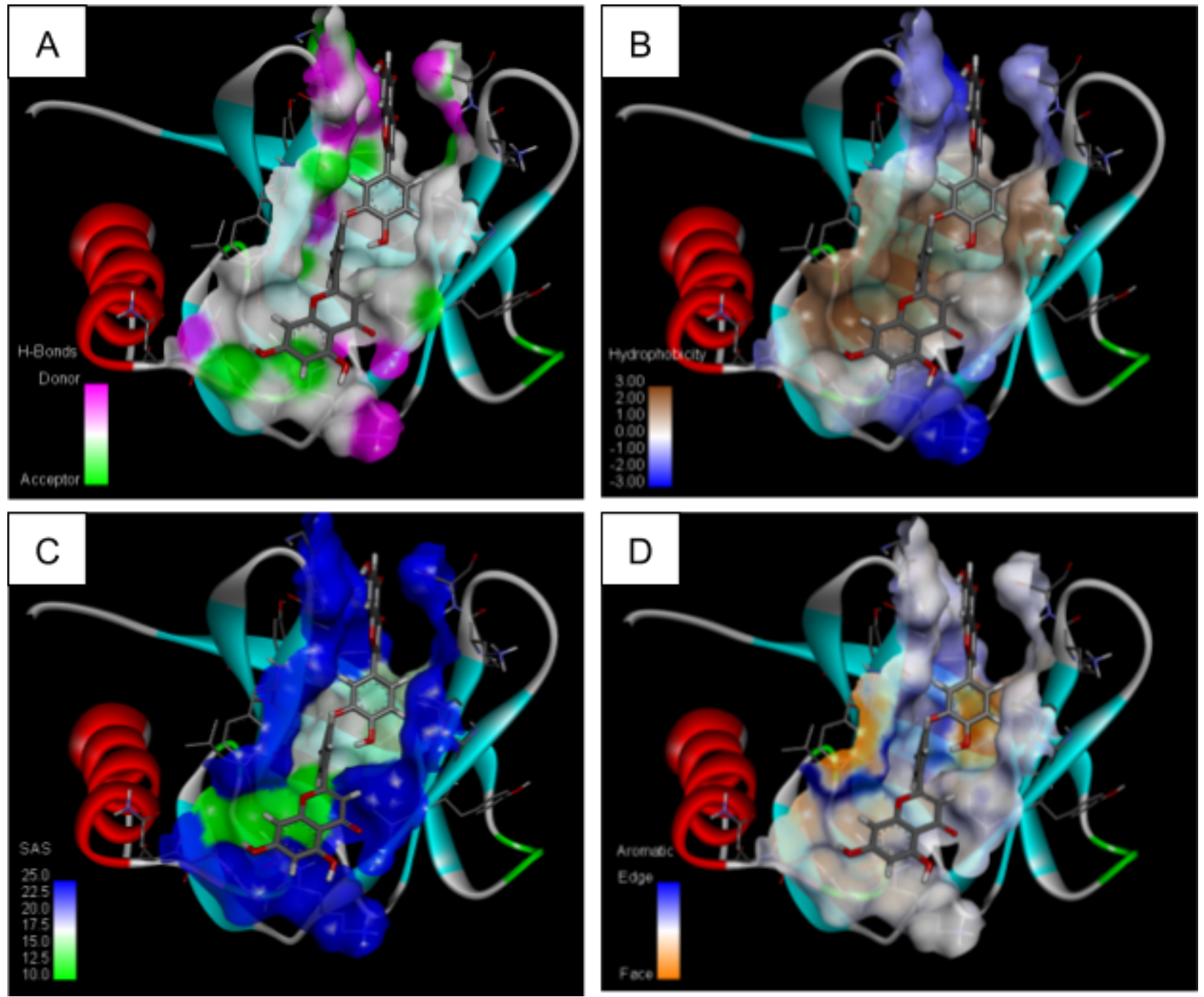

Figure 9. Representation of the characteristics including (A) distribution of H-bond donor/acceptor sites (B) Hydrophobicity (C) Solvent Accessibility and (D) Aromaticity across the surface of the binding site of NSP9 RNA replicase

\section{MM-GBSA Binding Energy of Top Inhibitors}

The molecular mechanics energies combined with generalized Born Surface Area (MM-GBSA) is one of the attractive approaches that is widely and successfully used to improve the docking scores and results of virtual screening, apart from reproducing experimental outcomes. Post-scoring compounds utilizing MM-GBSA have been shown to have a better correlation to their observed binding affinity when compared to docking (Tripathi, et al., 2013; Greenidge, et al., 2013). 
Docking scores are not always accurate, and the MM-GBSA method gives a better approach to estimate the free binding energies of the protein-ligand complexes with a notably higher degree of accuracy.

Table 7. MM-GBSA scores for the three inhibitors and the standard drug used as a control.

\begin{tabular}{|l|r|}
\hline Complex & $\begin{array}{l}\text { MMGBSA dG } \\
\text { Bind }\end{array}$ \\
\hline $\begin{array}{l}\text { Hispaglabridin } \\
\text { B }\end{array}$ & -42.88 \\
\hline Licoflavone B & -42.76 \\
\hline Ochnaflavone & -41.43 \\
\hline Verdinexor & -27.64 \\
\hline
\end{tabular}

The molecular docking scores that we obtained for Ochnaflavone, Hispaglabridin B, Licoflavone B, and Verdinexor against NSP9 were $-9.1 \mathrm{kcal} / \mathrm{mol},-8.5 \mathrm{kcal} / \mathrm{mol},-8.1 \mathrm{kcal} / \mathrm{mol}$, and $-7.7 \mathrm{kcal} / \mathrm{mol}$, respectively. We, however, observed differences in the binding energy evaluated using the MM-GBSA approach. Hispaglabridin B returned the highest MM-GBSA score of $-42.88 \mathrm{kcal} / \mathrm{mol}$, followed by Licoflavone B with $-42.76 \mathrm{kcal} / \mathrm{mol}$; both of them were higher than that of Ochnaflavone $(-41.43 \mathrm{kcal} / \mathrm{mol})$ as presented in Table 7 . Compared to the Vina docking scores, the top three inhibitors have been predicted to have better binding energy values when compared with the reference molecule (Verdinexor), suggesting even stronger binding.

\section{Molecular Dynamics Simulation Study}

In order to assess the protein-ligand complex stability for the top three inhibitors identified for NSP9, MD Simulations of 100 ns each were performed for Licoflavone B, Ochnaflavone, and Hispaglabridin. A 100 ns MD run for the free protein (apo-state) was also carried out. For the investigation of the stability, the root mean square deviation (RMSD) of the C $\alpha$ atoms of the protein and the ligand bound to the protein, root mean square fluctuations (RMSF) of the C $\alpha$ atoms of the protein. Also, of interest was understanding the dynamics of the protein-ligand contacts with time. 


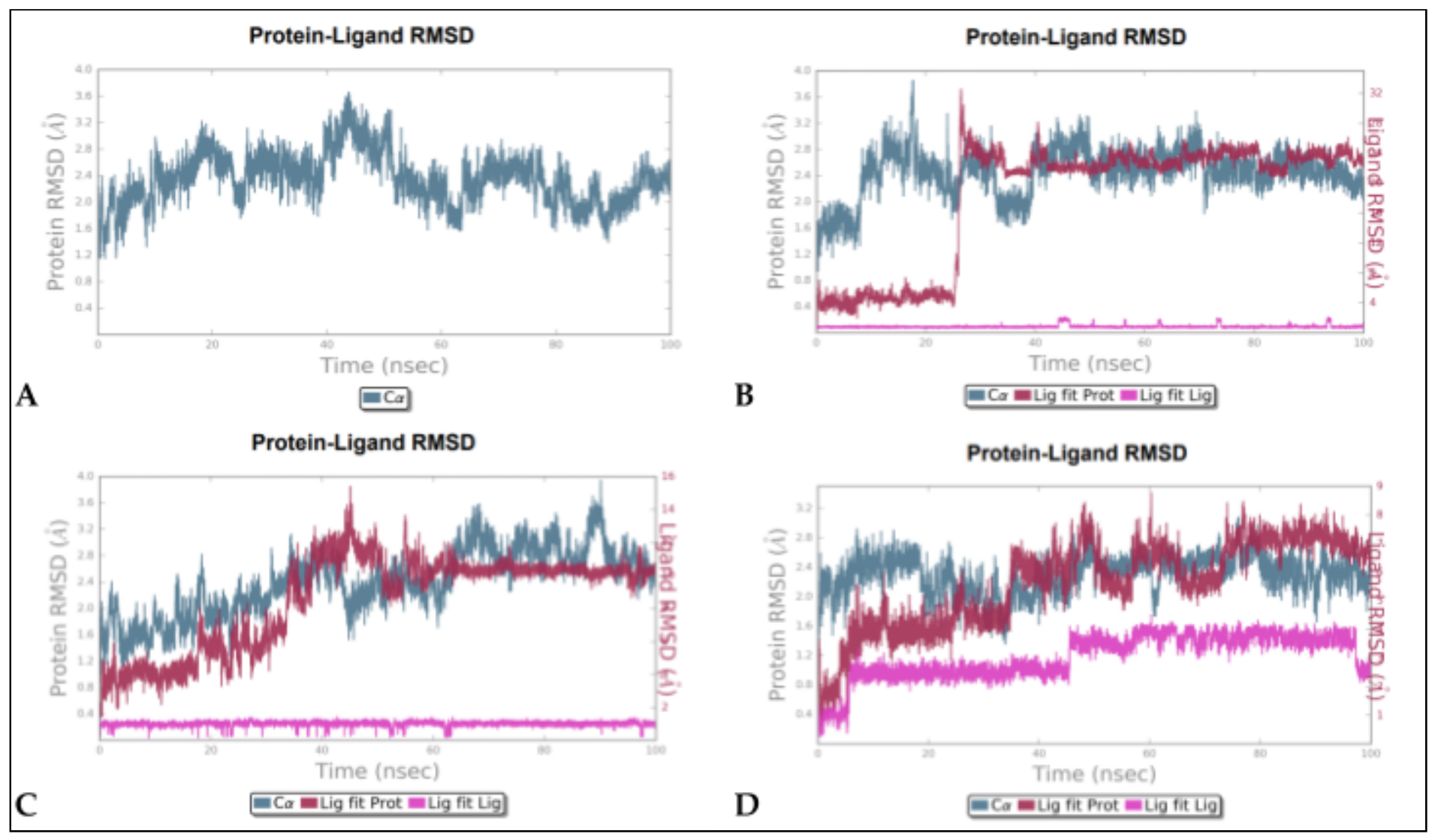

Figure 10. (A) RMSD of the apo-state of NSP9 (B) RMSD of NSP9 and Hispaglabridin B (C) RMSD of NSP9 and Licoflavone B (D) RMSD of NSP9 and Ochnaflavone. ['Lig fit Prot' shows the RMSD of a ligand when the protein-ligand complex is first aligned on the protein backbone of the reference, and then the RMSD of the ligand heavy atoms is measured. 'Lig fit Lig' shows the RMSD of a ligand that is aligned and measured just on its reference conformation.]

The RMSD values for NSP9 free state were within $1.20 \AA$ to $3.6 \AA$, while the average RMSD asymmetric carbon was $2.22 \AA$. The RMSD of the C $\alpha$ atoms of NSP9 is pretty stable for Ochnaflavone and Hispaglabridin B after $40 \mathrm{~ns}$, while for Licoflavone B, the stability is observed after 60 ns simulation run time. In the case of Licoflavone B (Figure 10C), a very stable RMSD of the ligand after 60ns was also observed. Hispaglabridin B (Figure 10B) showed a stark increase in its RMSD at around $25 \mathrm{~ns}$ and remains stable throughout the rest of the duration. This is perhaps due to a conformational change. On the other hand, Ochnaflavone showed a largely stable RMSD after 50 ns. Figure 11 shows the RMSF values of the apo-NSP9 and protein-ligand complexes. RMSF was employed to follow local changes along the NSP9 amino acid residues for the $100 \mathrm{~ns}$ simulation time. It was observed that the alpha helices and beta strands of the apo structure and docked systems oscillated within $0.8 \AA$ to $1.6 \AA$. The loop regions of all the simulated systems showed large fluctuations up to $4.8 \AA$, except for the apo state that showed change over $5.4 \AA$. Remarkably, there were no noteworthy instabilities in the loop regions when compared across the complexes. Understandably, the large fluctuations of the loops observed were due to their intrinsic flexible nature. Our results showed that the lead 
molecules complex with NSP9 were found to be stable in the binding site with negligible structural movements and lesser conformational changes to the overall enzyme structure, hence presenting them as potential inhibitors against NSP9.

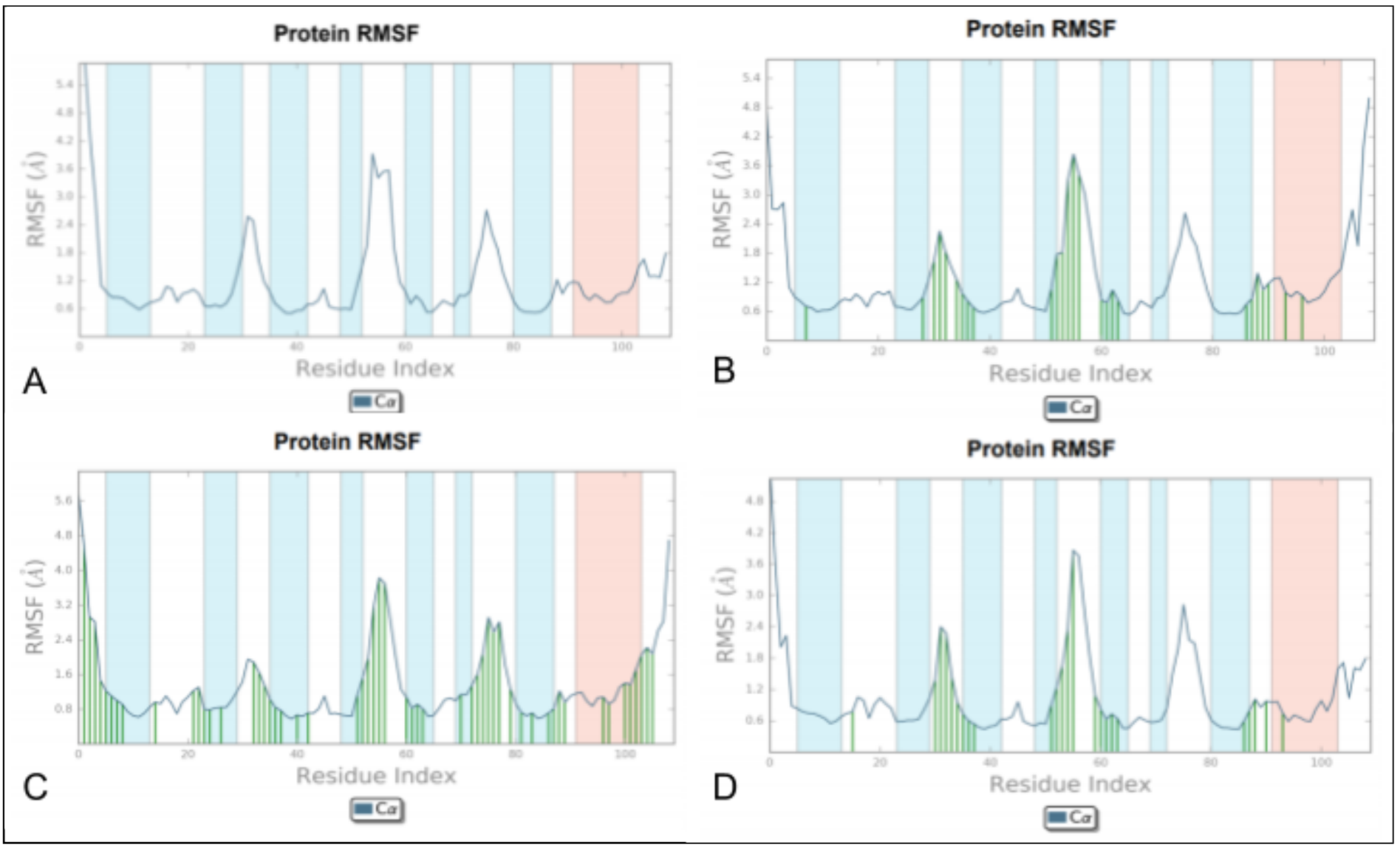

Figure 11. RMSF value of C $\alpha$ of (A) Apo-state NSP9, (B) NSP9-Licoflavone B, (C) NSP9-Hispaglabridin $\mathrm{B}$, and (D) NSP9-Ochnaflavone (from left to right) [Alpha-helical and beta-strand regions are highlighted in red and blue backgrounds, respectively. Protein residues that interact with the ligand are marked with green-colored vertical bars] 

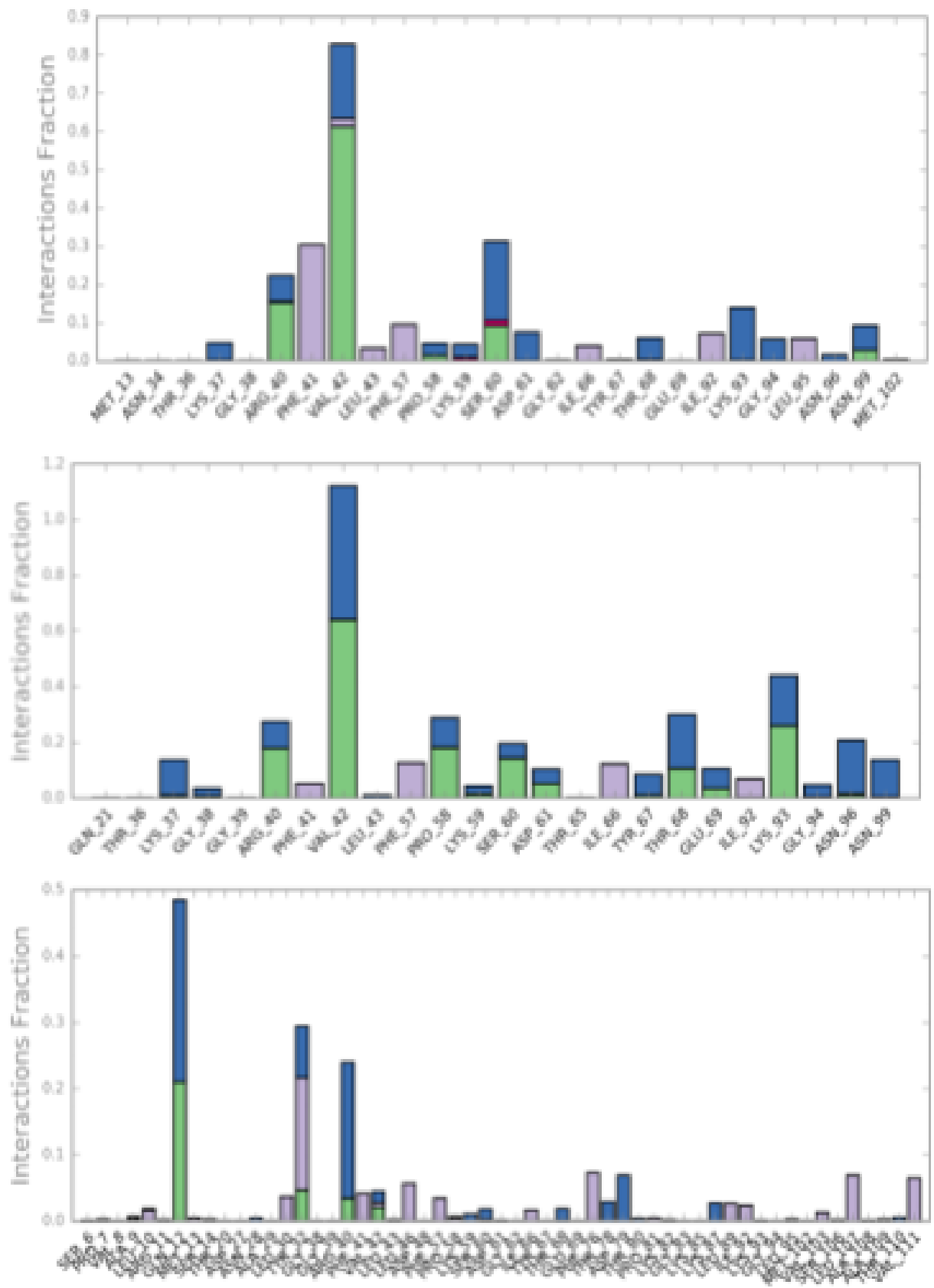

H-bonds $\square$ Hydrophobic $\square$ lonic $\square$ Water bridges

Figure 12. Protein-ligand contacts and interactions with the amino acid residues at the binding site of NSP9 in presence of ligands Licoflavone B, Ochnaflavone and Hispaglabridin B (top to bottom).

Upon analysis of the protein-ligand contacts, it was found that both Licoflavone B and Ochnaflavone have consistent H-bonding as well as H-bonding mediate by water interaction with VAL42 throughout the entire duration of 100ns of the simulation run. Licoflavone B was found to be in a prominent hydrophobic interaction with PHE41, while Ochnaflavone developed stable interactions with ASN96 and ASN99 via H-bonding mediated by water at 
$60 \%$ of the simulation run time. PRO58 and LYS93 are among the other important residues of contact for Ochnaflavone. Hispaglabridin B shows a variable interaction profile with the residues. It communicated with ARG40 via hydrogen bonding and water bridges at $26 \%$ at a time. Consistent interaction with GLN12 was maintained at 52\% through H-bonding together with water bridge contacts, and more robust interactions with TYR32 via H-bonding, water bridge, and hydrophobic contacts. Also, compared to Ochnaflavone and Licoflavone B, Figure 11 and Figure 12 Hispaglabridin B shows a much greater number of residues contact with NSP9 throughout the duration; however, most of the contacts were less than $10 \%$ the simulation time.

\section{Conclusion}

COVID-19 disease has remained a significant menace to the world, and the case to fatality percentage has remained on the rise. In order to tackle this menace, there is a need to develop therapeutic intervention rapidly. Here, extensive screening of our manually curated library via docking thresholds and stringent ADMET filters identified 5 leads for NSP9, and 23, 18, and 19 leads for Furin, ORF3a, and interleukin-6, respectively. Among the top five leads, Ochnaflavone, a biflavonoid extract from Lonicera japonica, and Licoflavone B, a flavonoid extract from Glycyrrhiza glabra showed promising polypharmacological prospects, as identified by their docking scores, ADMET properties, and binding interactions with the receptor site residues. Atomistic simulations of 100ns validated the stability of the Nsp9-Ligand complex. The current study comes up with convincing evidence about the antiviral and anti-inflammatory indications of these phytochemicals with great potential to inhibit simultaneous viral entry, replication, and disease progression, further opening up the quest for pre-clinical experimental studies.

\section{Declaration and conflict of interest}

The authors declare no conflict of interest.

\section{Acknowledgements}

The authors would like to thank BIOTRUST Scientific (http://biotrust.org.ng), CMESBAHF Nigeria (www.cmesbahf.ng), DNA Compass (www.dnacompass.co), Galaxy Project (http://usegalaxy.eu) and NELIREF for giving us the platform of HackBio for virtual collaboration and research.

\section{Supplementary information}

The supplementary file is available online at ChemRXiv.

\section{Funding}

The authors received no external funding for the work carried out.

\section{References}


Aanouz, I., Belhassan, A., El-Khatabi, K., Lakhlifi, T., El-Ldrissi, M., \& Bouachrine, M. (2020). Moroccan Medicinal plants as inhibitors against SARS-CoV-2 main protease: Computational investigations. Journal of Biomolecular Structure and Dynamics, 1-9.

Abbasifard, M., \& Khorramdelazad, H. (2020). The bio-mission of interleukin-6 in the pathogenesis of COVID-19: A brief look at potential therapeutic tactics. Life sciences, 118097. https://doi.org/10.1016/j.lfs.2020.118097

Shah, A. (2020). Novel Coronavirus-Induced NLRP3 Inflammasome Activation: A Potential Drug Target in the Treatment of COVID-19. Frontiers in Immunology, 11. DOI=10.3389/fimmu.2020.01021

Alomar, M. J. (2014). Factors affecting the development of adverse drug reactions. Saudi pharmaceutical journal, 22(2), 83-94. https://doi.org/10.1016/j.jsps.2013.02.003

Ashkenazy, H., Abadi, S., Martz, E., Chay, O., Mayrose, I., Pupko, T., \& Ben-Tal, N. (2016). ConSurf 2016: an improved methodology to estimate and visualize evolutionary conservation in macromolecules. Nucleic acids research, 44(W1), W344-W350. DOI: 10.1093/nar/gkw408; PMID: 27166375

Ashkenazy, H., Erez, E., Martz, E., Pupko, T., \& Ben-Tal, N. (2010). ConSurf 2010: calculating evolutionary conservation in sequence and structure of proteins and nucleic acids. Nucleic acids research, 38(suppl_2), W529-W533. DOI: 10.1093/nar/gkq399; PMID: 20478830

Abou Assi, R., Darwis, Y., Abdulbaqi, I. M., Vuanghao, L., \& Laghari, M. H. (2017). Morinda citrifolia (Noni): A comprehensive review on its industrial uses, pharmacological activities, and clinical trials. Arabian Journal of Chemistry, 10(5), 691-707. https://doi.org/10.1016/j.arabjc.2015.06.018.

Berman, H. M., Westbrook, J., Feng, Z., Gilliland, G., Bhat, T. N., Weissig, H., ... \& Bourne, P. E. (2000). The protein data bank. Nucleic acids research, 28(1), 235-242.

Bhardwaj, V. K., Singh, R., Sharma, J., Rajendran, V., Purohit, R., \& Kumar, S. (2020). Identification of bioactive molecules from Tea plant as SARS-CoV-2 main protease inhibitors. Journal of Biomolecular Structure and Dynamics, (just-accepted), 1-13.

BIOVIA, D. S. (2020). Discovery studio visualizer, Release 2017, San Diego: Dassault Systèmes, 2016. 2017.

Bradley C. Doak \& Jan Kihlberg (2017) Drug discovery beyond the rule of 5 - Opportunities and challenges, Expert Opinion on Drug Discovery, 12:2, 115-119, DOI: 10.1080/17460441.2017.1264385

Bowers, K. J., Chow, D. E., Xu, H., Dror, R. O., Eastwood, M. P., Gregersen, B. A., ... \& Salmon, J. K. (2006, November). Scalable algorithms for molecular dynamics simulations on commodity 
Polypharmacology of some medicinal plant metabolites against SARS-CoV-2 and host targets: Molecular dynamics evaluation of NSP9 RNA binding protein

clusters. In SC'06: Proceedings of the 2006 ACM/IEEE Conference on Supercomputing (pp. 43-43). IEEE.

Cameron, A., Appel, J., Houghten, R. A., \& Lindberg, I. (2000). Polyarginines are potent furin inhibitors. Journal of Biological Chemistry, 275(47), 36741-36749.

Castaño-Rodriguez, C., Honrubia, J. M., Gutiérrez-Álvarez, J., DeDiego, M. L., Nieto-Torres, J. L., Jimenez-Guardeño, J. M., ... \& Kochan, G. (2018). Role of severe acute respiratory syndrome coronavirus viroporins E, 3a, and 8a in replication and pathogenesis. MBio, 9(3).

Chan, J. F. W., Kok, K. H., Zhu, Z., Chu, H., To, K. K. W., Yuan, S., \& Yuen, K. Y. (2020). Genomic characterization of the 2019 novel human-pathogenic coronavirus isolated from a patient with atypical pneumonia after visiting Wuhan. Emerging microbes \& infections, 9(1), 221-236.

Channappanavar, R., \& Perlman, S. (2017, July). Pathogenic human coronavirus infections: causes and consequences of cytokine storm and immunopathology. In Seminars in immunopathology (Vol. 39, No. 5, pp. 529-539). Springer Berlin Heidelberg.

Chen, C. C., Krüger, J., Sramala, I., Hsu, H. J., Henklein, P., Chen, Y. M. A., \& Fischer, W. B. (2011). ORF8a of SARS-CoV forms an ion channel: experiments and molecular dynamics simulations. Biochimica et Biophysica Acta (BBA)-Biomembranes, 1808(2), 572-579.

Colson, P., Rolain, J. M., \& Raoult, D. (2020). Chloroquine for the 2019 novel coronavirus SARS-CoV-2. International journal of antimicrobial agents, 55(3), 105923.

Celniker, G., Nimrod, G., Ashkenazy, H., Glaser, F., Martz, E., Mayrose, I., ... \& Ben-Tal, N. (2013). ConSurf: using evolutionary data to raise testable hypotheses about protein function. Israel Journal of Chemistry, 53(3-4), 199-206.

Cucinotta, D., \& Vanelli, M. (2020). WHO declares COVID-19 a pandemic. Acta bio-medica: Atenei Parmensis, 91(1), 157-160.

Da-Costa-Rocha, I., Bonnlaender, B., Sievers, H., Pischel, I., \& Heinrich, M. (2014). Hibiscus sabdariffa L.-A phytochemical and pharmacological review. Food chemistry, 165, 424-443. https://doi.org/10.1016/j.foodchem.2014.05.002

Dahms, S. O., Arciniega, M., Steinmetzer, T., Huber, R., \& Than, M. E. (2016). Structure of the unliganded form of the proprotein convertase furin suggests activation by a substrate-induced mechanism. Proceedings of the National Academy of Sciences, 113(40), 11196-11201. https://doi.org/10.1073/pnas.1613630113

Darden, T., York, D., \& Pedersen, L. (1993). Particle mesh Ewald: An N · log (N) method for Ewald sums in large systems. The Journal of chemical physics, 98(12), 10089-10092.

doi:10.1063/1.464397. 
Rostro-Alanis, M. D. J., Báez-González, J., Torres-Alvarez, C., Parra-Saldívar, R.,

Rodriguez-Rodriguez, J., \& Castillo, S. (2019). Chemical composition and biological activities of oregano essential oil and its fractions obtained by vacuum distillation. Molecules, 24(10), 1904. https://doi.org/10.3390/molecules24101904

Dong, N., Yang, X., Ye, L., Chen, K., Chan, E. W. C., Yang, M., \& Chen, S. (2020). Genomic and protein structure modelling analysis depicts the origin and infectivity of 2019-nCoV, a new coronavirus which caused a pneumonia outbreak in Wuhan, China. BioRxiv.doi: https://doi.org/10.1101/2020.01.20.913368.

Ebhohimen, I. E., Edemhanria, L., Awojide, S., Onyijen, O. H., \& Anywar, G. (2020). Advances in computer-aided drug discovery. In Phytochemicals as Lead Compounds for New Drug Discovery (pp. 25-37). Elsevier. (2020) pp: 25-37.

Finch, A., \& Pillans, P. (2014). P-glycoprotein and its role in drug-drug interactions. Aust Prescr, 37(4), 137-139. DOI: 10.18773/austprescr.2014.050

Fontaine, V., SAVINO, R., ARCONE, R., De WIT, L., BRAKENHOFF, J. P., Content, J., \& CILIBERTO, G. (1993). Involvement of the Arg179 in the active site of human IL-6. European journal of biochemistry, 211(3), 749-755.

Geethangili, M., \& Ding, S. T. (2018). A Review of the Phytochemistry and Pharmacology of Phyllanthus urinaria L. Frontiers in pharmacology, 9, 1109. https://doi.org/10.3389/fphar.2018.01109

Becker, G. L., Sielaff, F., Than, M. E., Lindberg, I., Routhier, S., Day, R., ... \& Steinmetzer, T. (2010). Potent inhibitors of furin and furin-like proprotein convertases containing decarboxylated P1 arginine mimetics. Journal of medicinal chemistry, 53(3), 1067-1075. DOI: 10.1021/jm9012455

Greenidge, P. A., Kramer, C., Mozziconacci, J. C., \& Wolf, R. M. (2013). MM/GBSA binding energy prediction on the PDBbind data set: successes, failures, and directions for further improvement. Journal of chemical information and modeling, 53(1), 201-209.

Ghildiyal, R., Prakash, V., Chaudhary, V. K., Gupta, V., \& Gabrani, R. (2020). Phytochemicals as Antiviral Agents: Recent Updates. In Plant-derived Bioactives (pp. 279-295). Springer, Singapore.

Gil, C., Ginex, T., Maestro, I., Nozal, V., Barrado-Gil, L., Cuesta-Geijo, M. A., et al. (2020). COVID-19: Drug targets and potential treatments. Journal of Medicinal Chemistry. DOI: 10.1021/acs.jmedchem.0c00606

Gorbalenya, A. E., et al. (2020). Severe acute respiratory syndrome-related coronavirus: The species and its viruses-a statement of the Coronavirus Study Group. Microbiol. 5 (2020) 536-544. 
Gordon, D. E., Jang, G. M., Bouhaddou, M., Xu, J., Obernier, K., White, K. M., ... \& Tummino, T. A. (2020). A SARS-CoV-2 protein interaction map reveals targets for drug repurposing. Nature, 1-13. https://doi.org/10.1038/s41586-020-2286-9

Grubaugh, N. D., Petrone, M. E., \& Holmes, E. C. (2020). We shouldn't worry when a virus mutates during disease outbreaks. Nature Microbiology, 5(4), 529-530.

Grunewald, M. E., Fehr, A. R., Athmer, J., \& Perlman, S. (2018). The coronavirus nucleocapsid protein is ADP-ribosylated. Virology, 517, 62-68.

Gupta, M., \& Vaghela, J. S. (2019). Recent advances in pharmacological and phytochemistry studies on Phyllanthus amarus. Pharmaceutical and Biosciences Journal, 7(1), 01-08.

Gurung, A. B., Ali, M. A., Lee, J., Farah, M. A., \& Al-Anazi, K. M. (2020). Unravelling lead antiviral phytochemicals for the inhibition of SARS-CoV-2 Mpro enzyme through in silico approach. Life Sciences, 117831.

Hayashi, M., Rho, M. C., Enomoto, A., Fukami, A., Kim, Y. P., Kikuchi, Y., ... \& Omura, S. (2002). Suppression of bone resorption by madindoline A, a novel nonpeptide antagonist to gp130. Proceedings of the National Academy of Sciences, 99(23), 14728-14733.

Hong, S. S., Choi, J. H., Lee, S. Y., Park, Y. H., Park, K. Y., Lee, J. Y., ... \& Lee, K. (2015). A novel small-molecule inhibitor targeting the IL-6 receptor $\beta$ subunit, glycoprotein 130 . The Journal of Immunology, 195(1), 237-245.

Hossain, M. S., Urbi, Z., Sule, A., Rahman, K. M. H. (2014). Andrographis paniculata (Burm. f.) Wall. ex Nees: A Review of Ethnobotany, Phytochemistry, and Pharmacology, The Scientific World Journal, vol. 2014, Article ID 274905, 28. https://doi.org/10.1155/2014/274905.

Hussain, W., Haleem, K.S. , Khan, I., Tauseef, I. , Qayyum, S. , Ahmed, B. , Riaz, M.N. (2017). Medicinal plants: a repository of antiviral metabolites. Future Virology 12(6). 299-308.

Jendele, L., Krivák, R., Škoda, P., Novotný, M., Hoksza, D. (2019). PrankWeb: a web server for ligand binding site prediction and visualization. Nucleic Acids Research.

Kern, D.M. , Sorum, B., Hoel, C. M., et al. (2020). Cryo-EM structure of the SARS-CoV-2 3a ion channel in lipid nanodiscs. Preprint. bioRxiv. 2020;2020.06.17.156554. doi:10.1101/2020.06.17.156554

Kim, S., Chen, J., Cheng, T., Gindulyte, A., He, J., He, S., Li, Q., Shoemaker, B. A., Thiessen, P. A., Yu, B., Zaslavsky, L., Zhang, J., \& Bolton, E. E. (2019). PubChem 2019 update: improved access to chemical data. Nucleic acids research, 47(D1), D1102-D1109. https://doi.org/10.1093/nar/gky1033

Kiss, R., Sandor, M., Szalai, F. A. (2012). http://Mcule.com: a public web service for drug discovery. Journal of Cheminformatics. 4(Suppl 1):P17-P17. 
Krivák, R., Hoksza, D. (2018). P2Rank: machine learning based tool for rapid and accurate prediction of ligand binding sites from protein structure. Journal of Cheminformatics.

Lagunin, A., Zakharov, A., Filimonov, D., \& Poroikov, V. (2011). QSAR modelling of rat acute toxicity on the basis of PASS prediction. Molecular informatics, 30(2-3), 241-250.

Lambrakos, S.G., Boris, J.P., Oran, E.S., Chandrasekhar, I., Nagumo, M. (1989). A modified shake algorithm for maintaining rigid bonds in molecular dynamics simulations of large molecules. Journal of Computational Physics 1989, 85, 473-486, doi:10.1016/0021-9991(89)90160-5.

Leyva-López, N., Gutiérrez-Grijalva, E. P., Vazquez-Olivo, G., \& Heredia, J. B. (2017). Essential Oils of Oregano: Biological Activity beyond Their Antimicrobial Properties. Molecules (Basel, Switzerland), 22(6), 989. https://doi.org/10.3390/molecules22060989

Li, C. C., Wang, T.L., Zhang, Z. Q., Yang, W. Q., Wang, Y. F., Chai, X., Wang, C. H., Li, Z. (2016). Phytochemical and Pharmacological Studies on the Genus Psoralea: A Mini Review, Evidence-Based Complementary and Alternative Medicine, vol. 2016, Article ID 8108643, 17 pages. https://doi.org/10.1155/2016/8108643.

Li, X., Zai, J., Wang, X., Li, Y. (2020). Potential of large first generation human-to-human transmission of 2019-nCoV, Journal of medical virology, 92(4) 448-454.

Li, Y., Guo, S., Zhu, Y., Yan, H., Qian, D. W., Wang, H. Q., Yu, J. Q., Duan, J. A. (2019). Comparative analysis of twenty-five compounds in different parts of Astragalus membranaceus var. mongholicus and Astragalus membranaceus by UPLC-MS/MS. Journal of Pharmaceutical Analysis, Volume 9, Issue 6, Pages 392-399,ISSN 2095-1779, https://doi.org/10.1016/j.jpha.2019.06.002.

Lipinski, C. A., Lombardo, F., Dominy, B. W., \& Feeney, P. J. (1997). Experimental and computational approaches to estimate solubility and permeability in drug discovery and development settings. Advanced drug delivery reviews, 23(1-3), 3-25.

Liu, .A. L, Du, G. H. (2002). Antiviral properties of phytochemicals, Diet. Phytochem. Microbes, Springer, pp. 93-126.

Lu, B.J. , Zheng, K., Xu, W., Schwarz, L., Du, C. K., Wong, J., Chen, S., Duan, V., Deubel, B. S. (2006). Severe acute respiratory syndrome-associated coronavirus 3 a protein forms an ion channel and modulates virus release. Proc. Natl. Acad. Sci. USA 103 12540-12545.

Lynch, T., Price, A., (2007). The effect of cytochrome P450 metabolism on drug response, interactions, and adverse effects. Am Fam Physician. ;76(3):391-396.

Maestro-Desmond Interoperability Tools (2018). Schrödinger, New York, NY, 2018. 
Mamedov, N. A., Egamberdieva, D. (2019). Phytochemical Constituents and Pharmacological Effects of Licorice: A Review. In: Ozturk M., Hakeem K. (eds) Plant and Human Health, Volume 3. Springer, Cham. https://doi.org/10.1007/978-3-030-04408-4_1

Meng, X.Y., Zhang, H.X., Mezei, M., Cui, M., (2011). Molecular docking: a powerful approach for structure-based drug discovery, Curr. Comput. Aided. Drug Des. 7, 146-157.

Morris, G. M., Huey, R., Lindstrom, W., Sanner, M. F., Belew, R. K., Goodsell, D. S. and Olson, A. J. (2009) Autodock4 and AutoDockTools4: automated docking with selective receptor flexiblity. J. Computational Chemistry 2009, 16: 2785-91

Boyle, N.M.O., Banck, M., James, C A ., Morley, C., Vandermeersch, T., Hutchison, G R. (2011). Open Babel: An open chemical toolbox. J. Cheminf. 3, 33. DOI:10.1186/1758-2946-3-33

Naithani, R., Mehta, R.J., Shukla, D., Chandersekera, S. N., Moriarty, R. N. (2010). Antiviral activity of phytochemicals: a current perspective. In Dietary Components and Immune Function. Humana Press, Totowa, NJ, pp.421-468.

Newman, .D.J, Cragg, G.M. (2007). Natural products as sources of new drugs over the last 25 years, J. Nat. Prod. 70 461-477.

Nieto-Torres, J.L, DeDiego, M.L, Verdia-B 'aguena, J.M. 'Jimenez-Guardeño, J.A. Regla-Nava, R. Fernandez-Delgado, C., Castaño-Rodriguez, A., Alcaraz, J., Torres, V.M., Aguilella, L., Enjuanes, (2014). Severe acute respiratory syndrome coronavirus envelope protein ion channel activity promotes virus fitness and pathogenesis. PLoS Pathog. 10 e1004077.

Polish, N., Voytsakhivska, O., Marintsova, N., Zhurakhivska, L., Novikov, V., \& Bohza, S. (2019). Primary screening of the biological activity of heterocyclic aminoderivatives of 2, 3-dichloro-1, 4-naphtoquinone. ScienceRise: Pharmaceutical Science, (6 (22)), 37-42.

Ponnusamy, R., Moll, R., Weimar, T., Mesters, J. R., Hilgenfeld, R. (2008). Variable Oligomerization Modes in Coronavirus Non-structural Protein 9, Journal of Molecular Biology, Volume 383, Issue 5, Pages 1081-1096, ISSN 0022-2836, https://doi.org/10.1016/j.jmb.2008.07.071.

Proschak, E. (2014). In silico polypharmacology: retrospective recognition vs. rational design. J Cheminform 6, O25 https://doi.org/10.1186/1758-2946-6-S1-O25

Rahman, N.; Basharat, Z.; Yousuf, M.; Castaldo, G.; Rastrelli, L.; Khan, H. (2020). Virtual Screening of Natural Products against Type II Transmembrane Serine Protease (TMPRSS2), the Priming Agent of Coronavirus 2 (SARS-CoV-2). Molecules, 25, 2271.

Ren, Y., Shu, T., Wu, D. et al. (2020). The ORF3a protein of SARS-CoV-2 induces apoptosis in cells. Cell Mol Immunol 17, 881-883 https://doi.org/10.1038/s41423-020-0485-9

Riaz, M., Khan, O. , Sherkheli, M. A., Khan, M. Q. and Rashid, R. (2017). Chemical Constituents of Terminalia chebula, Nat Prod Ind J. 13(2):112 
Salata, C., Calistri, A., Parolin, C., Palù, G. (2020). Coronaviruses: A paradigm of new emerging zoonotic diseases. Pathogens and Disease, 77(9) 1-5.

Salman, S., Shah, F. H., Idrees, J., Idrees, F., Velagala, S., Ali, J., \& Khan, A. A. (2020). Virtual screening of immunomodulatory medicinal compounds as promising anti-SARS-COV-2 inhibitors. Future Virology, (0).

Sanner, M. F. (1999) Python: A Programming Language for Software Integration and Development. J. Mol. Graphics Mod., Vol 17, February. Pp57-61

Santos, T. G., Laemmle, J., Rebelo, R. A., Dalmarco, E. M., Cruz, A. B., Schmit, A. P., Cruz, R. C. B., Zeni, A. L. B., (2015). Chemical composition and antimicrobial activity of Aloysia gratissima (Verbenaceae) leaf essential oil, Journal of Essential Oil Research, 27:2, 125-130, DOI: 10.1080/10412905.2015.1006737

Schwarz, S., Wang, K., Yu, W., Sun, B., Schwarz, W. (2011). Emodin inhibits current through SARS-associated coronavirus 3a protein. Antiviral Res. ;90(1):64-69. doi:10.1016/j.antiviral.2011.02.008

Sethi, A., Joshi, K., Sasikala, K, Alvala, M. (2019). Molecular docking in modern drug discovery: principles and recent applications, Drug Discov. Dev. Adv, IntechOpen. DOI: 10.5772/intechopen.85991

Shang, X., Pan, H., Li, M., Miao, X., \& Ding, H. (2011). Lonicera japonica Thunb.: Ethnopharmacology, phytochemistry and pharmacology of an important traditional Chinese medicine. Journal of Ethnopharmacology, 138(1), 1.

Sharma, P., Dwivedee, B. P., Bisht, D., Dash, A. K., Kumar, D., (2019). The chemical constituents and diverse pharmacological importance of Tinospora cordifolia, Heliyon, Volume 5, Issue 9,2 e02437, ISSN 2405-8440, https://doi.org/10.1016/j.heliyon.2019.e02437.

Sievers, F., et al. (2011). Fast, scalable generation of high-quality protein multiple sequence alignments using Clustal Omega., Mol Syst Biol. ;7:539.

Silva, L. R., Pereira, M. J., Azevedo, J., Gonçalves, R. F., Valentão, P., Guedes. de Pinho P., Andrade, P. B. (2013). Glycine max (L.) Merr., Vigna radiata L. and Medicago sativa L. sprouts: A natural source of bioactive compounds, Food Research International, Volume 50, Issue 1, Pages 167-175, ISSN 0963-9969, https://doi.org/10.1016/j.foodres.2012.10.025.

Singh, D., Chaudhuri, P. K., (2018). A review on phytochemical and pharmacological properties of Holy basil (Ocimum sanctum L.), Industrial Crops and Products, Volume 118, Pages 367-382, ISSN 0926-6690, https://doi.org/10.1016/j.indcrop.2018.03.048.

Siu, K. L., Yuen, K. S., Castano-Rodriguez, C., et al., (2019). Severe acute respiratory syndrome Coronavirus ORF3a protein activates the NLRP3 inflammasome by promoting TRAF3-dependent ubiquitination of ASC. The FASEB Journal, 33(8) 8865-8877. 
Somers, W., Stahl, M. and Seehra, J.S. (1997), $1.9 \AA ̊$ crystal structure of interleukin 6: implications for a novel mode of receptor dimerization and signaling. The EMBO Journal, 16: 989-997. doi:10.1093/emboj/16.5.989

Somjen, D., Katzburg, S., Vaya, J., Kaye, A. M., Hendel, D., Posner, G. H., Tamir, S., (2004). Estrogenic activity of glabridin and glabrene from licorice roots on human osteoblasts and prepubertal rat skeletal tissues, The Journal of Steroid Biochemistry and Molecular Biology,Volume 91, Issues 4-5, Pages 241-246,ISSN 0960-0760, https://doi.org/10.1016/j.jsbmb.2004.04.008.

Surjit, M., Liu, B., Chow, V. T. K., Lal, S. K., (2006). The nucleocapsid protein of severe acute respiratory syndrome-coronavirus inhibits the activity of cyclin-cyclin-dependent kinase complex and blocks S phase progression in mammalian cells. J. Biol. Chem. 281, 10669-10681.

Sutton, G., Fry, E, Carter, L. et al., (2004). The nsp9 Replicase Protein of SARS-Coronavirus, Structure and Functional Insights. Structure. 12(2) 341-353. https://doi.org/10.1016/j.str.2004.01.016

Tan, Y.J. , Lim, S.G., Hong, W. (2006). Understanding the accessory viral proteins unique to the severe acute respiratory syndrome (SARS) coronavirus. Antiviral Res. 72 78-88.

Tan, K., Kim, Y., Jedrzejczak, R., Maltseva, N., Endres, M., Michalska, K., Joachimiak, A., (2020). Center for Structural Genomics of Infectious Diseases (CSGID), The crystal structure of Nsp9 RNA binding protein of SARS CoV-2 DOI: 10.2210/pdb6w4b/pdb

The Open Babel Package, version 2.3.1 http://openbabel.org

The PyMOL Molecular Graphics System, Version 2.3.4, Schrödinger, LLC.

The UniProt Consortium, (2019). UniProt: a worldwide hub of protein knowledge, Nucleic Acids Res. 47: D506-515

Tripathi, S. K., Muttineni, R., Singh, S. K. (2013). Extra precision docking, free energy calculation and molecular dynamics simulation studies of CDK2 inhibitors. Journal of Theoretical Biology $334: 87-100$.

Trott, O. \& Olson, A. J. (2010). AutoDock Vina: improving the speed and accuracy of docking with a new scoring function, efficient optimization, and multithreading. J Comput Chem 31, 455-461, https://doi.org/10.1002/jcc.21334

Tufan, A., GÜLER, A. A., Matucci-Cerinic, M., (2020). COVID-19, immune system response, hyperinflammation and repurposing antirheumatic drugs. Turkish Journal of Medical Sciences, 50(SI-1) 620-632. 
Umesh, K. D,, Selvaraj, C, Singh,S. K,, Dubey, V. K,, (2020). Identification of new anti-nCoV drug chemical compounds from Indian spices exploiting SARS-CoV-2 main protease as target. J. Biomol. Struct. Dyn. 1-9.

Velazquez-Salinas, L. , Zarate, S., Eberl, S., Gladue, D.P., Novella, I., Borca, M.V. (2020). Positive selection of ORF3a and ORF8 genes drives the evolution of SARS-CoV-2 during the 2020 COVID-19 pandemic. bioRxiv. doi: https://doi.org/10.1101/2020.04.10.035964

Venkatachallam, S. K. T., Pattekhan, H., Divakar, S., \& Kadimi, U. S. (2010). Chemical composition of Nigella sativa L. seed extracts obtained by supercritical carbon dioxide. Journal of Food Science and Technology, 47(6), 598.

World Health Organisation (2020). WHO Coronavirus disease (COVID-19) dashboard: Global situation. Available at https://covid19.who.int/.

Wrapp, D., Wang, N. , Corbett, K.S., et al., (2020). Cryo-EM structure of the 2019-nCoV spike in the prefusion conformation. Science, 367(6483) 1260-1263.

Wu, C., Liu, Y., Yang, Y., et al. (2020). Analysis of therapeutic targets for SARS-CoV-2 and discovery of potential drugs by computational methods. Acta Pharm Sin B. 10(5) 766-788.

Wu, F., Zhao, S., Yu, B., Y.M. et al. (2020). A new coronavirus associated with human respiratory disease in China. Nature 579 265-269.

Wu, K., Wang, C.-Z., Yuan, C.-S., \& Huang, W.-H. (2018). Oplopanax horridus: Phytochemistry and Pharmacological Diversity and Structure-Activity Relationship on Anticancer Effects. Evidence-Based Complementary and Alternative Medicine: eCAM, 2018. https://doi.org/10.1155/2018/9186926

Wu, Y., Guo, C. , Tang, L., Hong, Z., Zhou, J., Dong, X., Yin, H., Xiao, Q., Tang, Y., Qu, X., (2020). Prolonged presence of SARS-CoV-2 viral RNA in faecal samples The lancet Gastroenterology \& hepatology, 5 434-435.

Wu, C., Liu, Y., Yang, Y., Zhang, P., Zhong, W., Wang, Y., Wang, Q., Xu, Y., Li, M., Li, X., et al. (2020). Analysis of therapeutic targets for SARS-CoV-2 and discovery of potential drugs by computational methods. Acta Pharm. Sin. B 10, 766-788.

Yang, H., Lou, C., Sun, L., Li, J., Cai, Y., Wang, Z., Li, W., Liu, G., Tang, Y., (2019). admetSAR 2.0: web-service for prediction and optimization of chemical ADMET properties, Bioinformatics, Volume 35, Issue 6, Pages 1067-1069, https://doi.org/10.1093/bioinformatics/bty707

Zhang, M-Q., Wilkinson, B. (2007). Drug discovery beyond the 'rule-of-five'. Current Opinion in Biotechnology, 18(6):478-488. 
Zhang, X., Zhao, W., Wang, Y., Lu, J., Chen, X. (2016). The Chemical Constituents and Bioactivities of Psoralea corylifolia Linn.: A Review. The American Journal of Chinese Medicine, 35-60, 44, 01, DOI: 10.1142/S0192415X16500038

Zhao, T., Tang, H., Xie, L., Zheng, Y., Ma, Z., Sun, Q. and Li, X. (2019)., Scutellaria baicalensis Georgi. (Lamiaceae): a review of its traditional uses, botany, phytochemistry, pharmacology and toxicology. J Pharm Pharmacol, 71: 1353-1369. Doi: 10.1111/jphp.13129

Zhou, K., Wu, B., Zhuang, Y., Ding, L., Liu, Z., \& Qiu, F. (2009). Chemical constituents of fresh celery. China Journal of Chinese Materia Medica, 34(12). https://pubmed.ncbi.nlm.nih.gov/19777835/

Ziebuhr, J., Snijder, E. J., Gorbalenya, A. E. (2000). Virus-encoded proteinases and proteolytic processing in the Nidovirales. Journal of General Virology, 81(4) 853-879.

Zimmermann, P., Curtis, N. (2020). Coronavirus infections in children including COVID-19: An Overview of the Epidemiology, Clinical Features, Diagnosis, Treatment and Prevention Options in Children. Pediatr Infect Dis J.; 39(5):355-368. doi:10.1097/INF.0000000000002660

Zimmermann, L., Stephens, A., Nam, S. Z., Rau, D., Kübler, J., Lozajic, M., Gabler, F., Söding, J., Lupas, A. N., Alva, V. (2018). A Completely Reimplemented MPI Bioinformatics Toolkit with a New HHpred Server at its Core, J Mol Biol., S0022-2836(17)30587-9. 